\title{
Seizures and Sleep in the Thalamus: Focal Limbic Seizures Show Divergent Activity Patterns in Different Thalamic Nuclei
}

\author{
Li Feng, ${ }^{1,4}$ Joshua E. Motelow, ${ }^{1}$ Chanthia Ma, ${ }^{1}$ William Biche, ${ }^{1}$ CCian McCafferty, ${ }^{1}$ @Nicholas Smith, ${ }^{1}$ Mengran Liu, ${ }^{1}$ \\ Qiong Zhan, ${ }^{5}$ Ruonan Jia, ${ }^{1}$ Bo Xiao, ${ }^{4}$ Alvaro Duque, ${ }^{2}$ and Hal Blumenfeld ${ }^{1,2,3}$ \\ Departments of ${ }^{1}$ Neurology, ${ }^{2}$ Neuroscience, and ${ }^{3}$ Neurosurgery, Yale University School of Medicine, New Haven, Connecticut 06520, ${ }^{4}$ Department of \\ Neurology, Xiangya Hospital, Central South University, Changsha, Hunan 410008, China, and ${ }^{5}$ Department of Neurology, the Second Xiangya Hospital, \\ Central South University, Changsha, Hunan 410011, China
}

The thalamus plays diverse roles in cortical-subcortical brain activity patterns. Recent work suggests that focal temporal lobe seizures depress subcortical arousal systems and convert cortical activity into a pattern resembling slow-wave sleep. The potential simultaneous and paradoxical role of the thalamus in both limbic seizure propagation, and in sleep-like cortical rhythms has not been investigated. We recorded neuronal activity from the central lateral (CL), anterior (ANT), and ventral posteromedial (VPM) nuclei of the thalamus in an established female rat model of focal limbic seizures. We found that population firing of neurons in CL decreased during seizures while the cortex exhibited slow waves. In contrast, ANT showed a trend toward increased neuronal firing compatible with polyspike seizure discharges seen in the hippocampus. Meanwhile, VPM exhibited a remarkable increase in sleep spindles during focal seizures. Single-unit juxtacellular recordings from CL demonstrated reduced overall firing rates, but a switch in firing pattern from single spikes to burst firing during seizures. These findings suggest that different thalamic nuclei play very different roles in focal limbic seizures. While limbic nuclei, such as ANT, appear to participate directly in seizure propagation, arousal nuclei, such as CL, may contribute to depressed cortical function, whereas sleep spindles in relay nuclei, such as VPM, may interrupt thalamocortical information flow. These combined effects could be critical for controlling both seizure severity and impairment of consciousness. Further understanding of differential effects of seizures on different thalamocortical networks may lead to improved treatments directly targeting these modes of impaired function.

Key words: burst firing; consciousness; juxtacellular recording; sleep; temporal lobe epilepsy; thalamus

Significance Statement

Temporal lobe epilepsy has a major negative impact on quality of life. Previous work suggests that the thalamus plays a critical role in thalamocortical network modulation and subcortical arousal maintenance, but its precise seizure-associated functions are not known. We recorded neuronal activity in three different thalamic regions and found divergent activity patterns, which may respectively participate in seizure propagation, impaired level of conscious arousal, and altered relay of information to the cortex during focal limbic seizures. These very different activity patterns within the thalamus may help explain why focal temporal lobe seizures often disrupt widespread network function, and can help guide future treatments aimed at restoring normal thalamocortical network activity and cognition.

\section{Introduction}

Temporal lobe epilepsy is a common and debilitating neurological disorder, usually characterized by focal seizures with impaired consciousness. Patients typically exhibit repetitive motions and profoundly impaired consciousness during seizures

Received April 14, 2017; revised 0ct. 9, 2017; accepted 0ct. 14, 2017.

Author contributions: H.B. designed research; L.F., J.E.M., and W.B. performed research; N.S., Q.Z., R.J., B.X., and A.D. contributed unpublished reagents/analytic tools; L.F., C. Ma, C. McCafferty, and M.L. analyzed data; L.F. and H.B. wrote the paper.

This work was supported by National Institutes of Health Grants R01 NS066974, R01 NS096088, R21 NS083783, R21 NS093510, and P30 NS052519, the Loughridge Williams Foundation, and the Betsy and Jonathan Blattmachr Family. We thank Xiang He for assistance with computational analysis programming.

The authors declare no competing financial interests.
(Escueta et al., 1982; Blumenfeld, 2012). Previous human studies and animal research looking at the electrophysiological, fMRI, and metabolic data suggest that the thalamus, a key subcortical nucleus, receives most of the afferent inputs from the limbic system, brainstem, and other circuits participating in seizures. It then integrates, processes, and projects information to widespread cortical regions, playing a critical role in epilepsy-generating mechanisms in focal seizures and exerting a major influence on the thalamocortical

Correspondence should be addressed to Dr. Hal Blumenfeld, Yale University School of Medicine, Departments Neurology, Neuroscience, Neurosurgery, 333 Cedar Street, New Haven, CT 06520-8018. E-mail: hal.blumenfeld@yale.edu.

DOI:10.1523/JNEUROSCI.1011-17.2017

Copyright $\odot 2017$ the authors $\quad 0270-6474 / 17 / 3711441-14 \$ 15.00 / 0$ 
network and subcortical arousal systems (Redecker et al., 1997; Bertram et al., 1998; Benedek et al., 2004; Blumenfeld, 2014; He et al., 2015; Keller et al., 2015).

Recent work has highlighted the distinctions within thalamic structures, including the potential role of some nuclei in seizure propagation, whereas others contribute to impaired consciousness. A study of rodent limbic seizures reveals decreased BOLD fMRI signal in the intralaminar thalamus, which is strongly related to the suppression of cortical function, suggesting a possible role in modulation of consciousness (Motelow et al., 2015). Furthermore, high-frequency electrical stimulation in the intralaminar thalamus in rodent models can convert ictal or postictal cortical slow oscillations to an awake electrophysiological pattern and can also restore behavioral arousal (Gummadavelli et al., 2015b; Kundishora et al., 2017). In contrast, deep brain stimulation in the anterior nucleus of the thalamus (ANT) reduces seizure frequency in both animal and human studies (Mirski et al., 1997; Hamani et al., 2004; Lim et al., 2007; Salanova et al., 2015). However, the specific electrophysiological changes in different nuclei of the thalamus during focal limbic seizures have not been fully investigated.

To better define thalamic functions during focal limbic seizures, we chose three different thalamic nuclei involved in three key pathways, including arousal, sensory relay, and limbic networks, and investigated their specific electrophysiological changes in an established rodent seizure model. The central lateral (CL) nucleus of the thalamus, an important part of the rostral intralaminar thalamic nuclei, has been identified as a key region in the subcortical arousal systems for maintaining the level of consciousness (Van der Werf et al., 2002; Schiff et al., 2013). The ventral posteromedial nucleus (VPM) relays somatosensory-specific information for the face to the corresponding primary somatosensory cortex. The ANT, one of the most widely used deep brain stimulation sites for treatment of refractory epilepsy, provides a crucial bridge between prefrontal and limbic functions (Aggleton et al., 2010; Wright et al., 2013). We hypothesized that differential electrophysiological patterns would be noted across these three typical thalamic subregions. In particular, for CL and VPM, we predict specific neuronal firing patterns reflecting impaired conscious arousal and impaired information processing, whereas ANT may participate more directly in limbic seizure propagation.

We found that modulation of thalamic neuronal activity differs markedly by thalamic nuclei, suggesting they may serve divergent roles in the functional consequences of focal limbic seizures. Multiunit activity (MUA) in the CL showed decreased firing, whereas recordings from VPM were notable for an increase in sleep spindle waves during focal limbic seizures. Meanwhile, MUA in the ANT tended to show increased firing. Single-cell juxtacellular recordings from individual neurons in the CL showed decreased overall firing and a transition to a burst pattern, similar to thalamic-burst firing described previously during sleep due to enhanced low-threshold calcium spikes (Llinás and Steriade, 2006). These findings suggest that depressed arousal of the CL region of the thalamus may participate in suppressed activity of the cortex and loss of consciousness, whereas other nuclei participate in different functions during focal limbic seizures.

\section{Materials and Methods}

Animals

All procedures were conducted under approved protocols of Yale University's Institutional Animal Care and Use Committee. A total of 38 healthy adult female Sprague Dawley rats (Charles River Laboratories) weighing 180-280 g were used in these experiments. We chose female rats because our goal was to study focal limbic seizures without secondary generalization. Previous work from our laboratory and others has shown that secondary generalization is less likely in females than in males (MejíasAponte et al., 2002; Janszky et al., 2004). Thirty animals were used for MUA recordings in different nuclei of the thalamus (for CL, 30 seizures were recorded from 20 electrode sites in 9 rats; for ANT, 31 seizures were recorded from 26 sites in 10 rats; for VPM, 30 seizures were recorded from 22 sites in 11 rats). Eight rats were used for juxtacellular single-unit activity (SUA) recordings from thalamic CL (14 seizures from 12 neurons).

\section{Surgery and electrode implantation}

The animal model of focal limbic seizures was prepared as described previously (Englot et al., 2008). Animals were first deeply anesthetized with $90 \mathrm{mg} / \mathrm{kg}$ ketamine (Henry Schein Animal Health) and $15 \mathrm{mg} / \mathrm{kg}$ xylazine (AnaSed; Lloyd Laboratories) by intramuscular injection. Responsiveness to pain was checked every $15 \mathrm{~min}$ by toe pinch. A heating pad was used to keep the body temperature constant at $37^{\circ} \mathrm{C}$. All coordinates are reported in reference to bregma. A single tungsten monopolar microelectrode (UEWMGGSEDNNM; FHC) with an impedance of 3-4 $\mathrm{M} \Omega$ was implanted at an approach angle of 20 degrees from vertical in the right lateral orbitofrontal (LO) cortex targeting the following final coordinates: anteroposterior $4.2 \mathrm{~mm}$, mediolateral $2.2 \mathrm{~mm}$, superoinferior -4.2 (Paxinos and Watson, 1998). Twisted pair bipolar electrodes (50-100 k $\Omega$ resistance; Plastics One, E363/2-2TW) with tips separated by $1 \mathrm{~mm}$, insulation shaved from the distal $0.3 \mathrm{~mm}$, were implanted into the dorsal hippocampus (anteroposterior -3.8, mediolateral 2.5, superoinferior $-3.2 \mathrm{~mm}$ ) for stimulation and local field potential (LFP) signal recording. A steel screw $(0-80 \times 3 / 32$; Plastics One $)$ was implanted into the skull just caudal to the hippocampal burr hole to help fix the electrode by applying acrylic dental cement (Lang Dental Manufacturing, powder: REF 1220, jet liquid: REF 1403). For MUA recording in the CL, ANT, and VPM, monopolar tungsten microelectrodes (FHC, same model as above) were placed separately with the following coordinates: anteroposterior $-2.8 \mathrm{~mm}$, mediolateral $1.5 \mathrm{~mm}$, superoinferior -5.2 $\mathrm{mm}$ for CL; anteroposterior $-1.4 \mathrm{~mm}$, mediolateral $1.5 \mathrm{~mm}$, superoinferior $-5.6 \mathrm{~mm}$ for ANT; and anteroposterior $-3.3 \mathrm{~mm}$, mediolateral $2.4 \mathrm{~mm}$, superoinferior $-6.2 \mathrm{~mm}$ for VPM.

\section{Seizure initiation and MUA recording}

Seizure induction and electrophysiological recordings began $\sim 1-2 \mathrm{~h}$ postoperatively. The methods for induction of focal limbic seizures in light anesthesia were described in detail previously (Englot et al., 2008, 2009; Motelow et al., 2015). Seizures were induced from a lightly anesthetized state, where animals had recovered from deep anesthesia to a state with slow waves occurring at $\sim<3$ waves per $10 \mathrm{~s}$ of recording but remained unresponsive to toe pinch. A $2 \mathrm{~s}$ biphasic square pulse at $60 \mathrm{~Hz}$ in the hippocampus (1 ms/phase) was generated by an isolated pulse stimulator (A-M Systems, Model 2100) with current ranging from 100 to $900 \mu \mathrm{A}$. Focal seizures were obtained based on localized polyspike activity lasting at least $30 \mathrm{~s}$ in the hippocampus, and any seizures with secondary generalization based on propagation of polyspike activity to the frontal cortex were excluded from the analysis. Hippocampal LFP signals were amplified $(\times 1000)$ and filtered $(1-500 \mathrm{~Hz})$ using a Microelectrode AC Amplifier (A-M Systems, Model 1800). Thalamic CL, ANT, and VPM signals and cortical LO signals were broadband filtered from $0.1 \mathrm{~Hz}$ to $10 \mathrm{kHz}$ ( $\times 1000$ gain) using the same amplifier and then filtered with an analog filter (unity gain; Krohn-Hite, Model 3364) into either LFP $(0.1-100 \mathrm{~Hz})$ or MUA signals $(400 \mathrm{~Hz}$ to $10 \mathrm{kHz})$. All electrophysiology signals were digitized and recorded (sampling rate $1 \mathrm{kHz}$ for LFP, $20 \mathrm{kHz}$ for MUA) using a Power 1401 (CED) and Spike2 software (CED). At the conclusion of experiments, the locations of all electrodes were verified by histology (described below).

Juxtacellular recordings from the CL nucleus of the thalamus Animal preparation, electrode implantation in hippocampus and LO cortex, and seizure induction were conducted as already described for MUA recordings. Extracellular SUA recordings were acquired using the juxtacellular method (Pinault, 1996; Duque and Zaborszky, 2006; Motelow et al., 2015; Zhan et al., 2016). Briefly, glass electrodes were used to collect SUA data in the CL region at the same coordinates as above 
(anteroposterior $-2.8 \mathrm{~mm}$, mediolateral $1.5 \mathrm{~mm}$, superoinferior -5.2 $\mathrm{mm}$ ) with a micromanipulator (Sutter Instruments, MPC-325). The 1.5 $\mathrm{mm} \times 100 \mathrm{~mm}$ borosilicate glass capillaries (\#1B150F-4, World Precision Instruments) were pulled on a Flaming/Brown micropipette puller (Sutter Instruments, P-1000 horizontal puller), which were then bumped under a microscope to produce a flat electrode tip and filled with $4 \%$ Neurobiotin (Vector Laboratories, SP-1120) in saline $(0.9 \% \mathrm{NaCl})$. Only electrodes with a resistance of $15-30 \mathrm{M} \Omega$ were used during experiments. An Axoclamp-2B amplifier (Molecular Devices, $\times 10$ gain, currentclamp mode) was used to acquire SUA signals digitized at $20,000 \mathrm{~Hz}$ with a Power 1401 and Spike2 software (CED). Once a neuron signal was stably recorded during the baseline, ictal, and postictal periods, it would be labeled by passing current pulses $(0.6-10 \mathrm{nA}$, pulse duration $150 \mathrm{~ms}$, $3 \mathrm{~Hz}$ ) through the electrode tip to eject the Neurobiotin as described previously (Duque and Zaborszky, 2006; Motelow et al., 2015; Zhan et al., 2016). Cells were driven by current pulses for at least $15 \mathrm{~min}$ to obtain good labeling. Locations of recorded cells were obtained by histology as described in the next section.

\section{Immunohistochemistry and microscopy}

Animals were perfused transcardially with $0.2 \%$ heparinized PBS (APP Pharmaceuticals) followed by 4\% PFA (JT Baker) in PBS. The brain was then removed and postfixed overnight in $4 \%$ PFA in PBS at $4^{\circ} \mathrm{C}$. After being washed three times in PBS, the block of tissue containing the cells and electrode tracts of interest was dissected. Coronal sections $60-\mu \mathrm{m}-$ thick were cut with a Vibratome (Leica Microsystems). For identification of recording sites by electrode tracts alone, slices were mounted on polarized slides and stained with cresyl violet (FD NeuroTechnologies). For identification of juxtacellularly recorded neurons by nickel stain, sections were incubated for $10 \mathrm{~min}$ in $0.7 \%$ hydrogen peroxide in cold PBS (to block peroxidases), and then in biotinylated peroxidase (1:200, "B" component of standard $\mathrm{ABC}$ [avidin-biotin peroxidase complex] kit, Vector Laboratories) overnight. Using DAB as a chromogen, the neuron was then intensified with nickel $(\mathrm{Ni})$ by incubating the sections in a solution containing $0.05 \% \mathrm{DAB}$ and $0.038 \%$ nickel ammonium sulfate for $5 \mathrm{~min}$ and then adding hydrogen peroxide to a final concentration of $0.01 \%$, and agitating for an additional $5 \mathrm{~min}$. The slices were then rinsed thoroughly to remove any Ni-DAB deposits outside the labeled neuron. Slices were mounted on polarized slides (ThermoScientific) and dried for at least $48 \mathrm{~h}$. Finally, they were stained with cresyl violet using a manufacturer-recommended protocol for reagents (FD NeuroTechnologies) to confirm neuron locations. Slides were coverslipped with Permount (Fisher Chemicals). Images of slices were taken on a compound light microscope (Carl Zeiss) with a digital camera (Motic), and digitally stitched together (Microsoft Image Composite Editor). Positively stained neurons were identified based on display of black-deep brown color from Ni-DAB. Neuron locations in the CL were confirmed when they fell no more than $1.5 \mathrm{~mm}$ ventral to the hippocampus, and were just lateral to the stria medullaris/lateral habenula complex or the mediodorsal thalamic nucleus.

\section{Data analysis}

MUA, spindle power, and LFP delta power analysis. Analysis epochs were defined as follows: baseline was the last $10 \mathrm{~s}$ of recording immediately preceding seizure onset; ictal was the first $30 \mathrm{~s}$ of the seizure period (defined based on polyspike discharges in the hippocampal LFP); postictal was the first $10 \mathrm{~s}$ after seizure offset; and recovery was the last $10 \mathrm{~s}$ of recording before either the animal required reanesthesia or the experiment was terminated. MUA signals were processed further using Spike2 (CED). For analyzing MUA signal amplitude in the CL, ANT, and VPM during focal seizures, the root mean square voltage (Vrms) was measured in consecutive overlapping $1 \mathrm{~s}$ time bins. Use of Vrms analysis of MUA has been validated in previous studies of epilepsy models and under normal conditions, and closely matches neuronal firing based on spike sorting (Shmuel et al., 2006; Englot et al., 2008; Schridde et al., 2008).

Spindle waves are well-characterized $7-14 \mathrm{~Hz}$ thalamocortical oscillations lasting 1-3 s with a crescendo/decrescendo amplitude profile, seen most prominently in thalamic relay nuclei and corresponding cortical regions (Contreras and Steriade, 1996). To identify and quantify the amount of spindle wave activity in CL and VPM, we used the typical pattern of transient rhythmic MUA firing, which more readily distinguished spindles from other more sustained $7-14 \mathrm{~Hz}$ activity seen on LFP recordings. In Spike2 (CED), we first downsampled the MUA from 20 $\mathrm{kHz}$ to $100 \mathrm{~Hz}$. Because the MUA signals were already bandpass filtered from $400 \mathrm{~Hz}$ to $10 \mathrm{kHz}$ (described above), this provided an amplitude profile of MUA corresponding to the $7-14 \mathrm{~Hz}$ spindle activity with most of the other contaminating $7-14 \mathrm{~Hz}$ signals from the LFP removed. We next calculated the 7-14 Hz power in the downsampled MUA signal in 2.56 s overlapping bins to obtain "spindle power."

To monitor electrophysiology changes in cortex with focal limbic seizures, we chose to record from the $\mathrm{LO}$ frontal cortex because this region exhibits typical ictal and postictal $1-3 \mathrm{~Hz}$ slow-wave activity as well as changes in functional neuroimaging, which are also present in other widespread cortical regions in both animal models and human studies (Blumenfeld et al., 2004a; Englot et al., 2008, 2009; 2010; Gummadavelli et al., 2015a; Motelow et al., 2015; Kundishora et al., 2017). In Spike2 (CED), we calculated the delta (0-4 $\mathrm{Hz}$ ) power in the LO LFP signal in $1 \mathrm{~s}$ overlapping bins.

Statistical analysis of MUA, spindle power, and LFP delta power. To show a time course of mean percent changes for MUA or spindle and delta power, we plotted [(signal during focal seizure - mean baseline)/mean baseline] $\times 100 \%$, for consecutive $1 \mathrm{~s}$ nonoverlapping intervals. Average MUA Vrms, spindle power, and LFP delta power signal changes in each epoch (baseline, ictal, postictal, recovery) were calculated for statistical analysis. When analyzing data from multiple seizures in multiple animals, there are trade-offs in potential bias introduced by either analyzing data across all seizures weighted equally (can overemphasize an animal with outlier values if it has many seizures) or pooling within animal first (can overemphasize a seizure with outlier values if it occurs in an animal with few seizures). Therefore, we analyzed all results using both approaches. Figures shown here were generated by pooling seizures within each animal first because this approach is generally more conservative due to lower sample sizes ( $n=$ number of animals rather than number of seizures). However, very similar results were obtained when each analysis was repeated across all seizures (data not shown).

Repeated-measures ANOVA was used to detect electrophysiological changes in CL, ANT, VPM, and LO by contrasting values in the preseizure baseline with the ictal, postictal, and recovery epochs. All statistical tests were performed using SPSS 17 (IBM), and significance level was set at $p<0.05$.

SUA analysis. Spike sorting on the juxtacellular recordings was performed using Spike2 (CED, version 5.20a) to identify single units using waveform shapes based on template matching. Recordings were then analyzed using in-house software written on MATLAB (R2009a, The MathWorks). Raster plot for neuron firing and burst firing were analyzed during epochs of baseline ( $10-0 \mathrm{~s}$ before stimulus), seizure period (the first $10 \mathrm{~s}$ of hippocampal seizure activity based on polyspike activity in the LFP recordings), and the postictal period ( $0-10 \mathrm{~s}$ after seizure). Analyses were performed only on neurons identified by juxtacellular staining or by electrode tracts localized to the CL by histology. Histograms of mean firing rate were calculated across neurons in $1 \mathrm{~s}$ nonoverlapping bins for each epoch, and statistical analyses performed as already described for MUA.

Interspike interval (ISI) analysis. The ISI was calculated as the time (in milliseconds) between two consecutive action potentials in the SUA recordings, an approach commonly used in the analysis of neuronal firing patterns and to detect burst firing (Chen et al., 2009). We defined burst firing as $\geq 2$ consecutive action potentials with an ISI $\leq 10 \mathrm{~ms}$ (Kros et al., 2015). Logarithmic ISI histograms were then analyzed using in-house software written in MATLAB (R2009a, The MathWorks). We compared the proportion of action potentials that occurred in tonic (nonburst) and burst firing patterns in the baseline, ictal, and postictal periods (same definitions as for SUA analysis) by $\chi^{2}$ analysis with Bonferroni-corrected significance threshold $p<0.05$.

\section{Results \\ MUA decreases in the CL of the thalamus during focal limbic seizures}

MUA, which reflects the aggregate spiking activity of a population of neurons, is informative in deciphering the brain's com- 


\section{A}
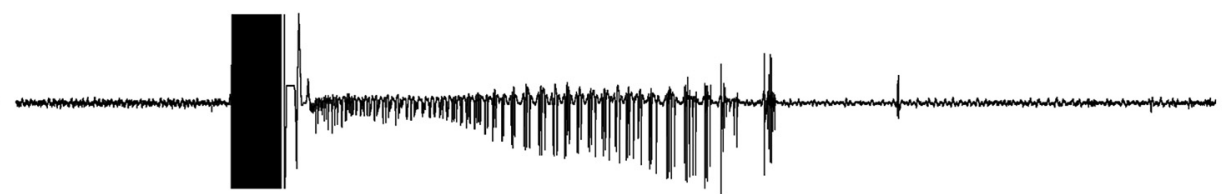

$1000 \mu \mathrm{V}$

CL MUA

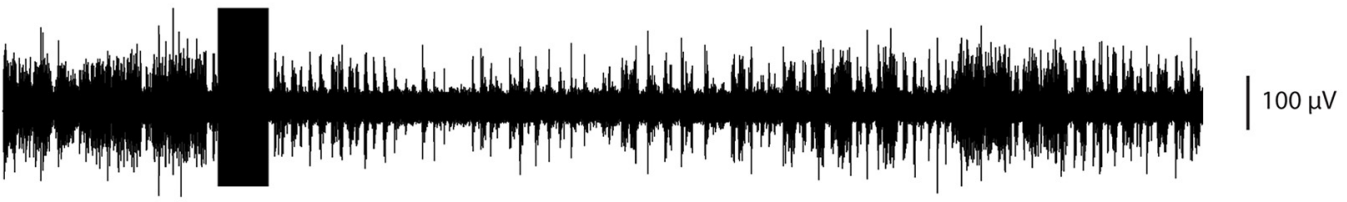

LO LFP

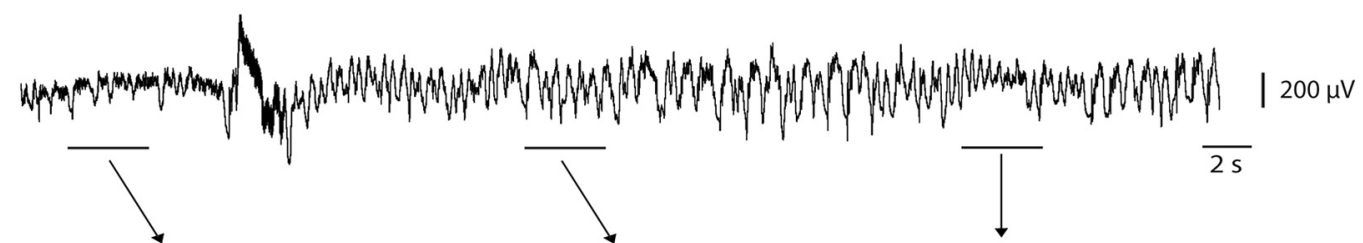

B

Baseline

Ictal

Postictal

HC LFP

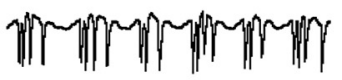

CL MUA
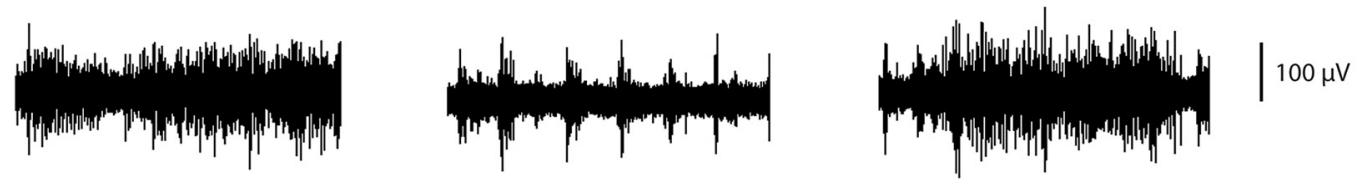

LO LFP
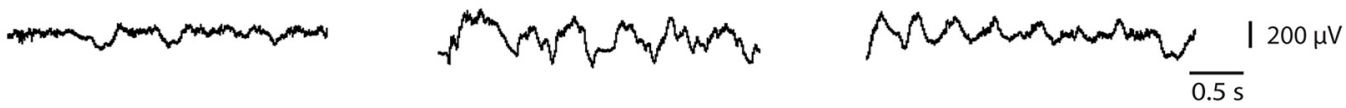

C1

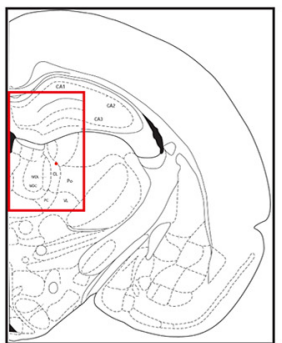

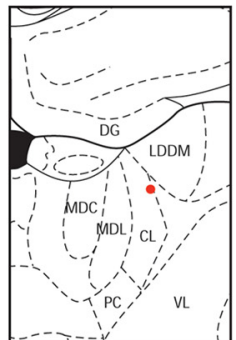

Bregma -2.3mm

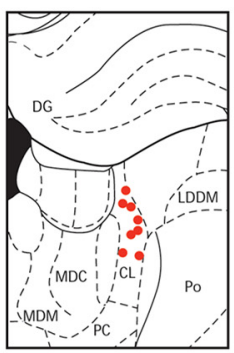

Bregma $-3.3 \mathrm{~mm}$

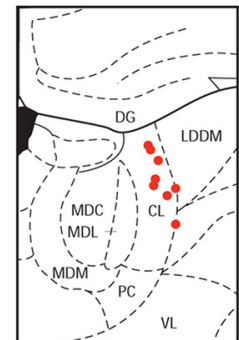

Bregma $-2.8 \mathrm{~mm}$

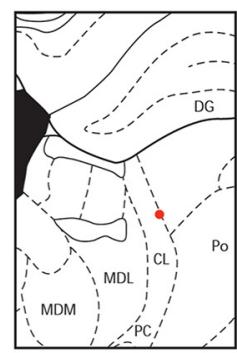

Bregma $-3.6 \mathrm{~mm}$

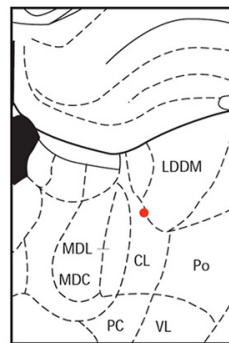

Bregma $-3.14 \mathrm{~mm}$

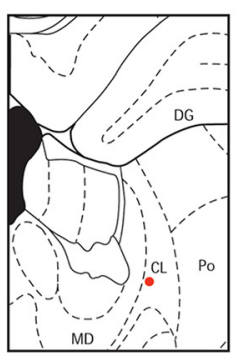

Bregma $-3.8 \mathrm{~mm}$

Figure 1. Decreased MUA in thalamic $C L$ nucleus during focal limbic seizure. $A$, Seizure induced by $2 s$ stimulation of the hippocampus. After the stimulus, fast polyspike activity is seen in the hippocampal local field potential (HCLFP). MUA from thalamic C Lucleus reflects marked suppression of neuronal firing during the ictal period with gradual recovery in the postictal period. LO frontal cortex shows slow-wave activity in the ictal period, which also gradually recovered postictally. $\boldsymbol{B}$, Expanded segments of data from baseline, ictal, and postictal epochs are magnified from the labeled region in $\boldsymbol{A}$. C, Histology example from thalamic CL nucleus MUA recording, coronal section at anteroposterior $\sim-3.14 \mathrm{~mm}$. C1, Red box represents general region where the electrode tract tip is located. C2, Expanded view of red box in C1, showing electrode tip in thalamic CL stained by cresyl violet. D, Schematic summary of electrode tip locations in CL (red) from all experiments included in the MUA analysis in Figure $2 A$ ( $n=9$ animals, 20 recording sites). MD, Mediodorsal nucleus of thalamus; MDL, mediodorsal nucleus of thalamus, lateral part; MDM, mediodorsal nucleus of thalamus, medial part; MDC, mediodorsal nucleus of thalamus, central part; LDDM, laterodorsal nucleus of thalamus, dorsomedial part; $\mathrm{PC}$, paracentral nucleus of thalamus; $\mathrm{VL}$, ventrolateral nucleus of thalamus; Po, posterior nuclear group of thalamus; DG, dentate gyrus. Coronal atlas sections reproduced with permission from Paxinos and Watson (1998). 

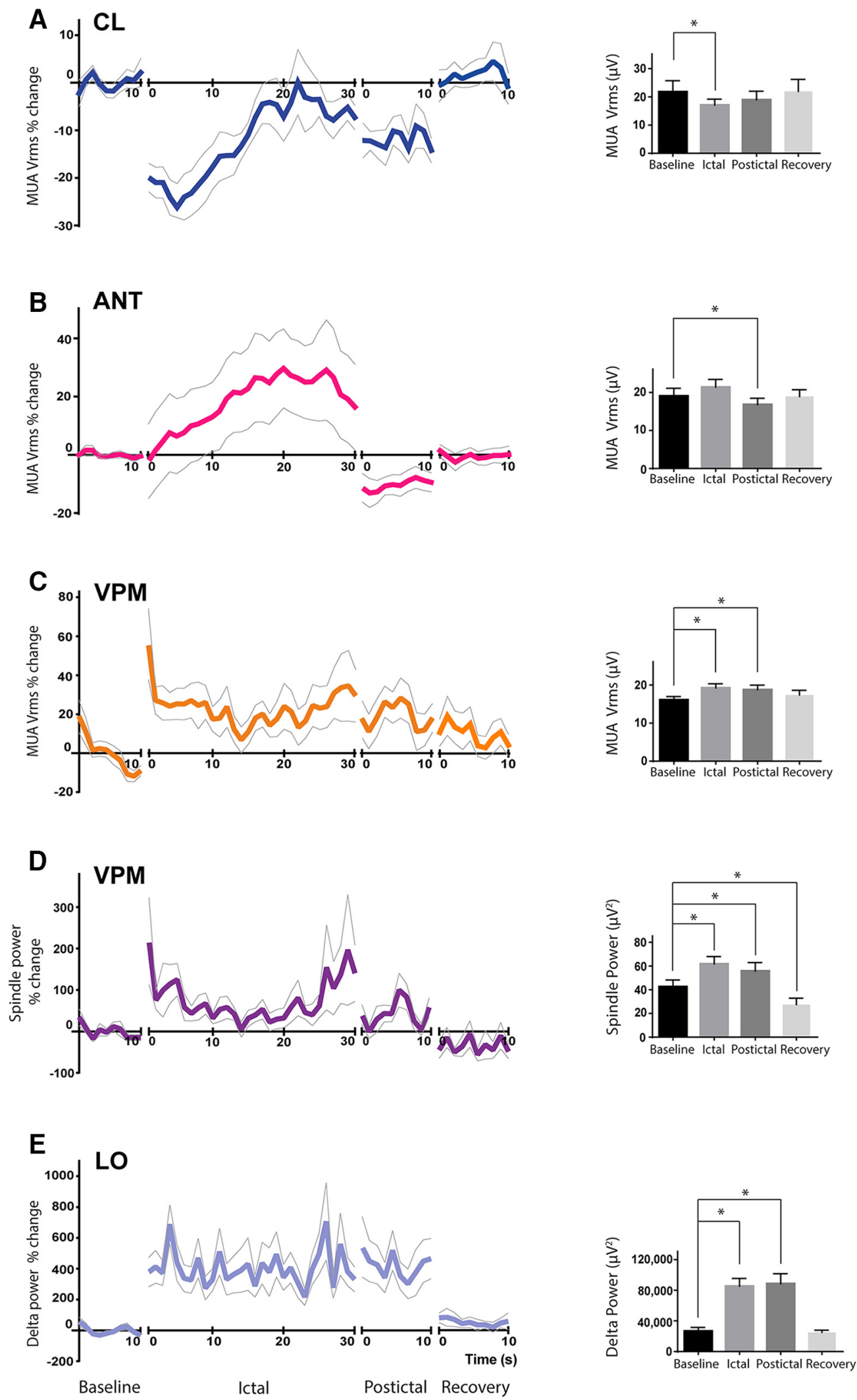

Figure 2. Mean time courses of thalamic activity in focal limbic seizures. $A$, In the thalamic $C L$ nucleus, MUA Vrms decreased during the ictal period compared with preseizure baseline, and then gradually recovered during the postictal period. Data are from 9 animals, 30 seizures. $B$, MUA changes in the ANT showed an opposite trend to those in CL. MUA tended to increase during the ictal period, was suppressed postictally, and then recovered toward baseline. Data are from 10 animals, 31 seizures. C, MUA Vrms in the thalamic VPM nucleus increased during ictal period and then gradually recovered during the postictal period. Data are from 11 animals, 30 seizures. $\boldsymbol{D}$, In the thalamic VPM nucleus, spindle power $(7-14 \mathrm{~Hz})$ increased in the ictal period compared with preseizure baseline. Data are from 11 animals, 30 seizures. $E$, Time course of delta-band $(0-4 \mathrm{~Hz})$ power before, during, and after seizures. Compared with preseizure baseline, delta power in the lateral orbitofrontal cortex greatly increased in the ictal and postictal periods, finally returned in the recovery epoch. Data are from 30 animals, 91 seizures. $A-E$, Data are for $10 \mathrm{~s} \mathrm{baseline} \mathrm{epochs}$ immediately preceding seizures, $30 \mathrm{~s}$ ictal epochs starting immediately after seizure onset, $10 \mathrm{~s}$ postical epochs immediately after seizure end, and (Figure legend continues.) 
plex time-varying response to stimuli or to clinical insults. We targeted our MUA recordings first to the intralaminar CL nucleus of the thalamus (CL) because this region has been identified as a key nucleus in the subcortical arousal system and plays a critical and unique function in regulating arousal, attention, and goaldirected behavior (Van der Werf et al., 2002). In our experiments, the animals would be initially anesthetized to surgical depth and then were allowed to recover to a light anesthesia level indicated by a predominance of cortical fast activity in LFP as described previously (Englot et al., 2008, 2009). Focal limbic seizures were then induced with a $2 \mathrm{~s}$ hippocampal stimulation. Slow oscillations in LFP with up and down states in MUA were recorded in the LO frontal cortex. Electrophysiological recordings were performed during 30 focal seizures from the thalamic CL in 9 animals. MUA was markedly reduced during the ictal period and gradually recovered toward baseline following seizures (Figs. $1 A, B, 2 A)$. On average, MUA amplitude in the CL was significantly reduced during focal limbic seizures $(p<0.05$; Fig. $2 A$, inset) and gradually recovered in the postictal and recovery periods. Unlike VPM (discussed below), we did not observe spindle waves in CL during our recordings, and there were no significant changes in spindle frequency $(7-14 \mathrm{~Hz})$ power in CL during or after seizures (data not shown). Locations of electrodes were determined histologically by cresyl violet staining (Fig. $1 C, D)$.

\section{MUA tends to increase in the ANT of the thalamus during focal seizures}

The ANT is a key component of cortical-subcortical limbic circuitry, including the hippocampal system for episodic memory. It has direct connections with 3 different episodic memory subsystems involving the hippocampus, mammillary bodies, and neocortex (Child and Benarroch, 2013). Based on MUA recording results from 10 animals, 31 seizures in total, we found that neurons in the ANT region of the thalamus were observed to have a trend toward increased firing during seizures (Fig. $3 A, B$ ). Unlike the changes in CL, average MUA amplitude in the ANT demonstrated an increase during seizures in 8 of 11 animals. This overall increase was statistically significant when data were analyzed across seizures (data not shown) but did not reach significance when data were first pooled within animals and then analyzed across animals. (Fig. $2 B$, inset), although the postictal suppression of MUA in ANT did reach significance. Locations of all electrodes in the ANT were determined histologically by cresyl violet staining (Fig. 3C,D).

\section{MUA and spindle waves increase in the VPM during focal seizures}

Sleep spindles are major transient oscillations of the mammalian brain. Previous studies have suggested that spindles are generated in the thalamus during states of low arousal, such as sleep or deafferentation from subcortical modulatory arousal systems, and are especially prominent in thalamic relay nuclei, such as the VPM (Steriade and Deschenes, 1984; von Krosigk et al., 1993). We found that, during the baseline lightly anesthetized period, just before seizure initiation, occasional isolated spindle waves were re-

$\leftarrow$

(Figure legend continued.) 10 s recovery epochs. Left time courses, Mean \pm SEM, with $1 \mathrm{~s} \mathrm{time}$ bins. Time $=0$ for the ictal period, seizure onset. Right histograms, Mean values for each epoch. Error bars indicate SEM. Data were averaged first within animals and then analyzed by repeated-measures ANOVA, contrasting baseline versus each of the other epochs. ${ }^{*} p<0.05$. corded in VPM, characterized by a crescendo-decrescendo pattern of 7-14 Hz rhythmic activity lasting 2-3 s (Fig. 4A) and accompanied by similar spindle wave activity in the corresponding somatosensory cortex (data not shown). Interestingly, when a seizure was triggered, the occurrence of spindle waves markedly increased during the ictal and postictal periods, resulting also in an increase in overall MUA in the ictal and postictal periods, which later recovered (Figs. 2C,D, 4A,B). Based on recordings from 11 animals in 30 focal seizures, we observed that the spindle band (7-14 $\mathrm{Hz}$ ) power and MUA Vrms in VPM were significantly increased ictally and postictally in focal limbic seizures compared with baseline ( $p<0.05$; Fig. $2 C, D$, insets). Locations of all electrodes in the VPM were determined histologically by cresyl violet staining (Fig. 4C,D).

\section{Increases in cortical LO LFP delta power accompany thalamic changes}

Previous work has shown that, during focal limbic seizures, the cerebral cortex exhibits widespread slow-wave activity along with reduced cerebral blood flow representing depressed cortical activity (Blumenfeld et al., 2004a; Englot et al., 2008, 2009; 2010; Motelow et al., 2015). In the present study, we therefore monitored the large-amplitude slow waves that are prominent in the cortical LFP by quantifying delta-band power $(0-4 \mathrm{~Hz})$ in epochs immediately before, during, and after seizures (Fig. $2 E$ ). We found that the neuronal activity changes in thalamic nuclei during focal seizures were accompanied by increased delta power in the lateral orbital frontal cortex in the ictal and postictal periods $(p<$ 0.05 ; Fig. $2 E$, inset), which subsequently recovered to baseline.

\section{Single neurons in the thalamic CL show decreased firing and a conversion to a burst-firing pattern during focal seizures}

Our MUA data showed decreased population neuronal firing in the thalamic CL during focal seizures. However, the firing pattern of individual neurons in this region was not clear. Therefore, we conducted juxtacellular recordings of single neurons (SUA) in the CL. We found that single neurons in the CL fired regularly before seizure initiation but markedly decreased their firing almost immediately after seizure onset (Fig. 5). In the postictal period, the firing rate of thalamic CL neurons gradually began to recover back to baseline. Meanwhile, as reported previously (Englot et al., 2008, 2009; Motelow et al., 2015) during focal hippocampal seizures, the cortical MUA converted to up and down states, whereas cortical LFP showed prominent slow oscillations (Fig. $5)$. The locations of all SUA recordings in CL were confirmed by histology (Fig. 6). SUA recordings from neurons in the CL as a group (12 neurons from 8 animals, 14 seizures) displayed a consistent and dramatic decrease in firing during seizures (Fig. $7 A, B$ ). Although they possessed variable firing rates at baseline, 11 of 12 neurons (91.6\%) decreased their firing rates during seizures and slowly recovered during the postictal period. On average, SUA firing rate decreased by $51.87 \pm 19.29 \%$ (mean \pm SEM) during the first $10 \mathrm{~s}$ of seizures compared with $10 \mathrm{~s}$ preictal baseline $(p<0.05)$.

Interestingly, almost all neurons identified in the CL by histology fired tonically with single spikes before seizure onset but after seizure initiation immediately converted to burst firing of two or more spikes (Figs. 5C,D, 7C-E). Enhanced burst firing of thalamic CL neurons gradually recovered in the postictal period (Fig. 7C). Defining bursts as two or more spikes with ISI $<10 \mathrm{~ms}$, we found the proportion of spikes in burst firing pattern was significantly higher in both the ictal and postictal periods compared with baseline $\left(\chi^{2}=634.1,223.6\right.$, respectively, $\left.p<0.0001\right)$ 
A

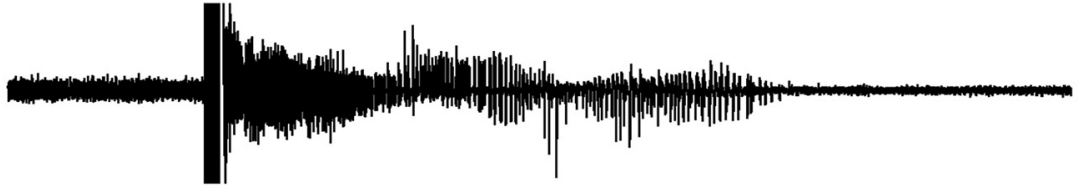

ANT MUA

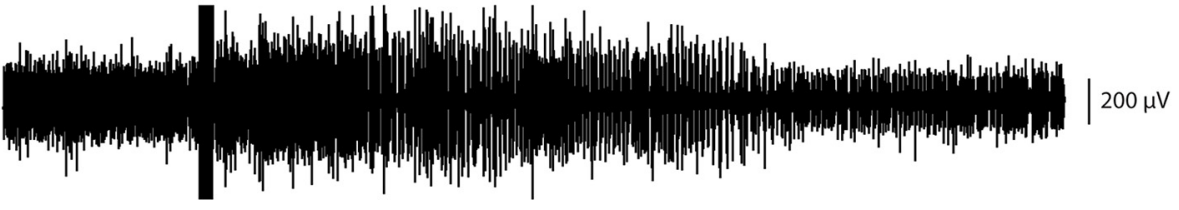

LO LFP

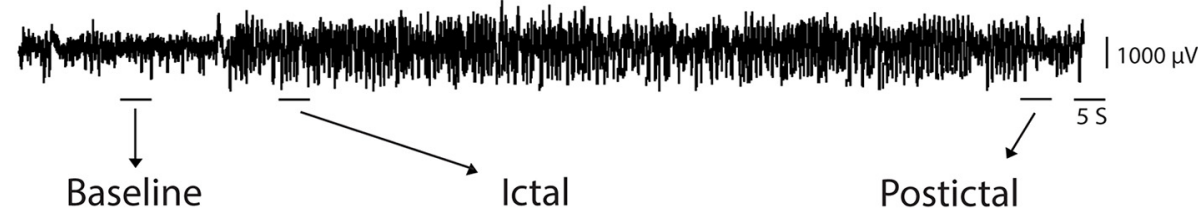

HC LFP
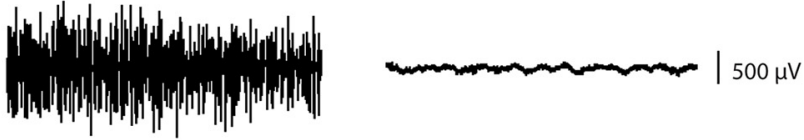

ANT MUA

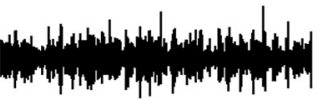

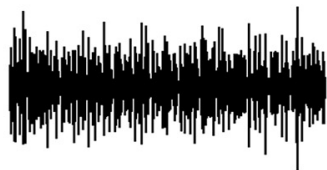

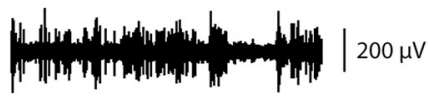

LO LFP
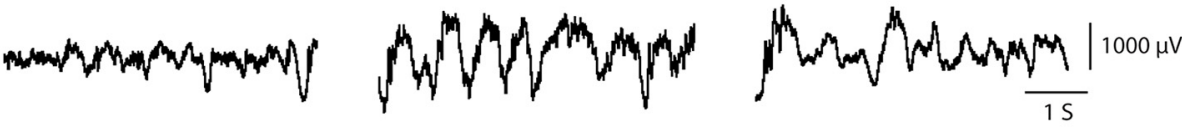

C1

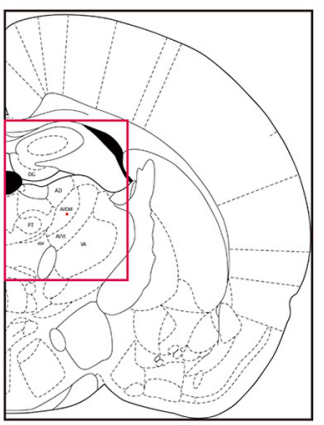

D

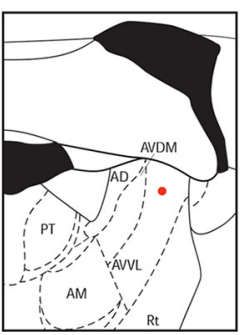

Bregma $-1.3 \mathrm{~mm}$

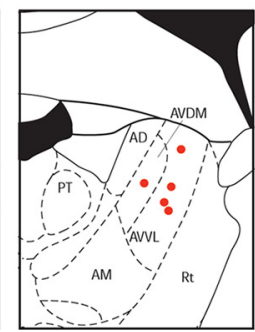

Bregma $-1.4 \mathrm{~mm}$

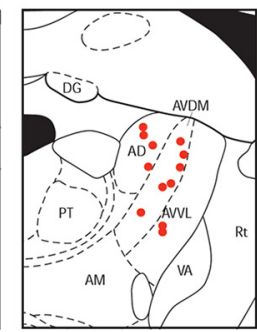

Bregma $-1.6 \mathrm{~mm}$

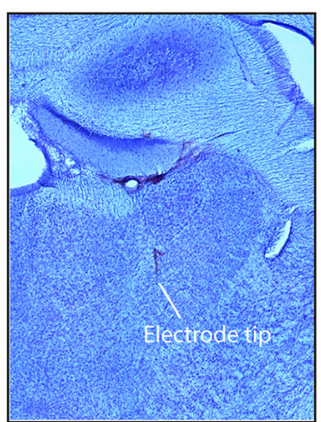

Bregma $-1.8 \mathrm{~mm}$

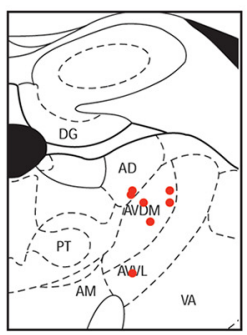

Bregma $-1.8 \mathrm{~mm}$

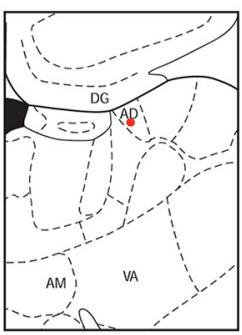

Bregma $-2.1 \mathrm{~mm}$

Figure 3. Example showing increased MUA in ANT during focal limbic seizure. $\boldsymbol{A}$, Seizure induced by 2 s stimulation of the hippocampus. After the stimulus, fast polyspike activity is seen in the hippocampal LFP (HC LFP). MUA recording from ANT shows increased firing during the seizure, which slowly recovered in the postictal period. L0 frontal cortex shows slow-wave activity in the ictal period, which persisted postictally and gradually recovered at later times (data not shown). $\boldsymbol{B}$, Expanded segments of data from baseline, ictal, and postictal epochs are magnified from the labeled region in $\boldsymbol{A}$. C, Histology example from ANT MUA recording, coronal section at anteroposterior $\sim-1.8 \mathrm{~mm}$. $\mathbf{C}$, Red box represents general region where the electrode tract tip is located. C2, Expanded view of red box in C1, showing electrode tip in ANT stained by cresyl violet. D, Schematic summary of electrode tip locations in ANT (red) from all experiments included in the MUA analysis in Figure $2 B$ ( $n=10$ animals, 26 recording sites). AM, Anteromedial nucleus of thalamus; AD, anterodorsal nucleus of thalamus; AVDM, anteroventral (Figure legend continues.) 
A

HC LFP
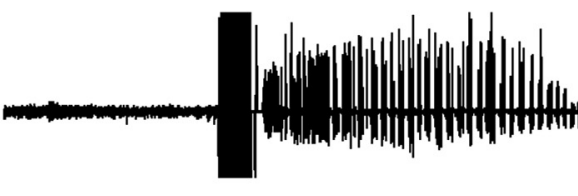

$2000 \mu \mathrm{V}$

VPM MUA

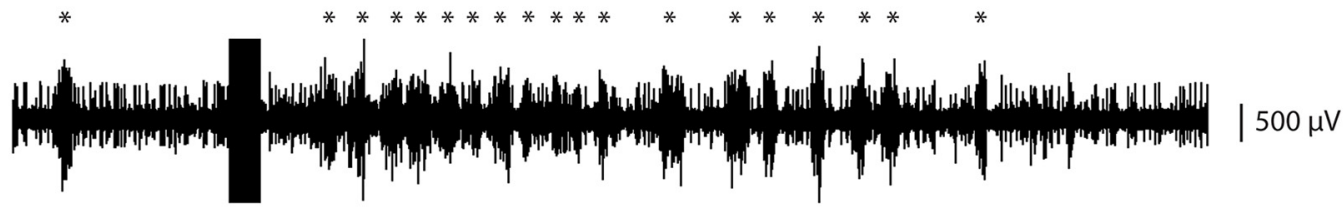

LO LFP

B

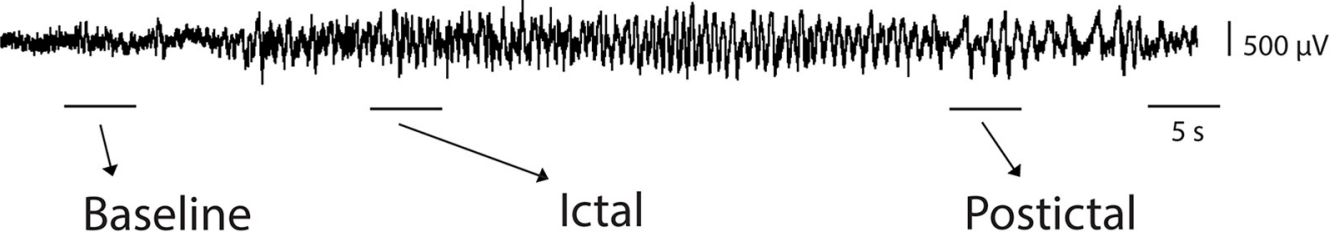

HC LFP

VPM MUA

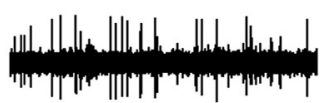

LO LFP
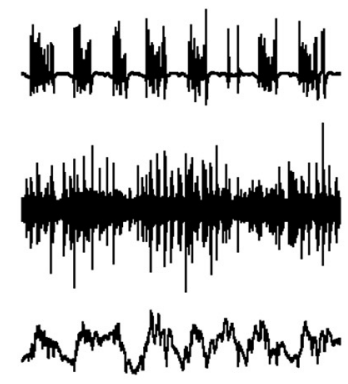

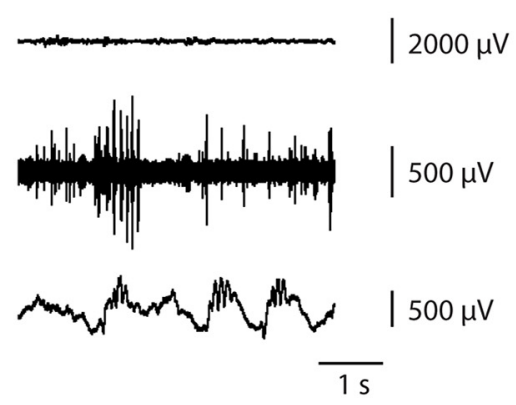

C1

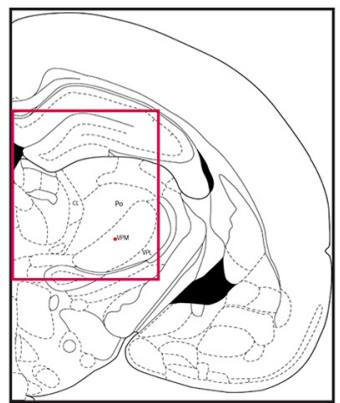

Bregma $-3.6 \mathrm{~mm}$
C2

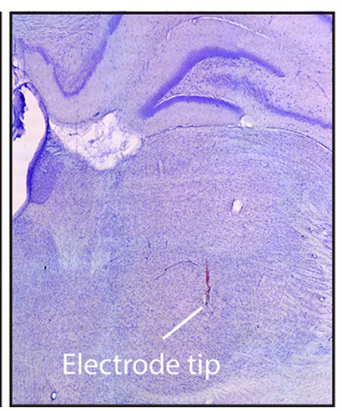

Bregma $-3.6 \mathrm{~mm}$

D

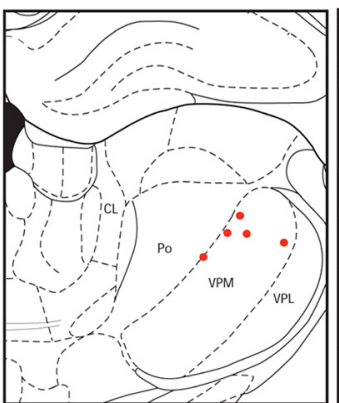

Bregma -3.3mm

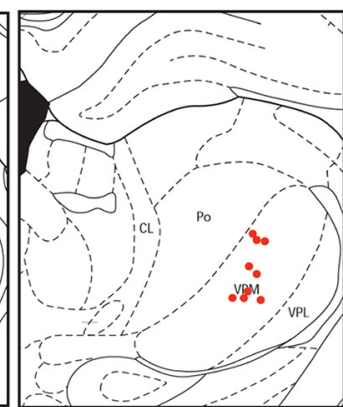

Bregma $-3.6 \mathrm{~mm}$

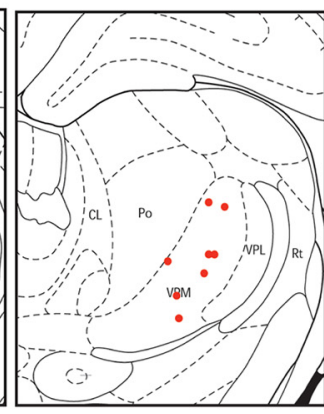

Bregma $-3.8 \mathrm{~mm}$

Figure 4. Increased spindle wave activity in thalamic ventral posterior medical nucleus during focal limbic seizure. $\boldsymbol{A}$, Seizure induced by $2 \mathrm{~s}$ stimulation of the hippocampus. After the stimulus, fast polyspike activity is seen in the hippocampal LFP (HC LFP). MUA recording from thalamic VPM nucleus is notable for an increase in spindle waves during focal seizures, which gradually returned to baseline following the postictal period. *Each spindle wave. LO frontal cortex shows slow-wave activity in the ictal period, which also gradually recovered postictally. $\boldsymbol{B}$, Expanded segments of data from baseline, ictal, and postictal epochs are magnified from the labeled region in $A$. C, Histology example from thalamic VPM MUA recording, coronal section at anteroposterior $\sim-3.6 \mathrm{~mm}$. C1, Red box represents general region where the electrode tract tip is located. C2, Expanded view of red box in C1, showing electrode tip in thalamic VPM stained by cresyl violet. D, Schematic summary of electrode tip locations in VPM (red) from all experiments included in the analysis of spindle waves in Figure $2 C(n=11$ animals, 22 recording sites). VPM, VPM nucleus of thalamus; CL, CL nucleus of thalamus; Po, posterior nuclear group of thalamus; VPL, ventral posterior lateral nucleus of thalamus; Rt, reticular nucleus of thalamus. Coronal atlas sections reproduced with permission from Paxinos and Watson (1998).

(Figure legend continued.) nucleus of thalamus, dorsomedial part; AVVL, anteroventral nucleus of thalamus, ventrolateral part; PT, paratenial nucleus of thalamus; Rt, reticular nucleus of thalamus; VA, ventral ANT; DG, dentate gyrus. Coronal atlas sections reproduced with permission from Paxinos and Watson (1998).
(Fig. $7 D, E$ ). This dramatic change in firing pattern, from tonic to burst firing during seizures, tended to gradually recover toward tonic firing in the postictal period.

\section{Discussion}

We investigated neuronal activity in the CL, ANT, and VPM of the thalamus during the peri-ictal periods in an established rodent model through induced focal limbic seizures. Using MUA 
A HC LFP

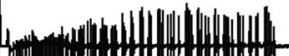
证

CL SUA

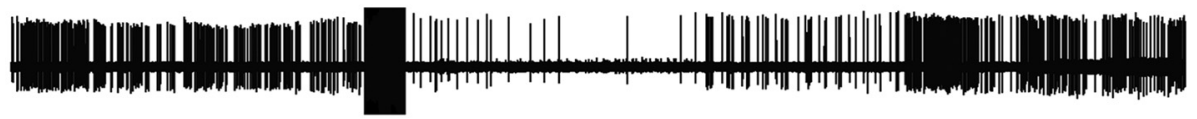

I $2000 \mu \mathrm{V}$

LO MUA

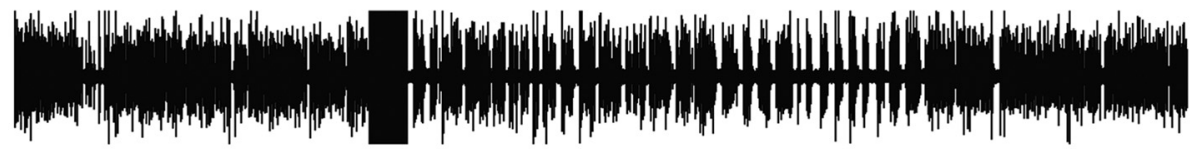

| $100 \mu \mathrm{V}$

LO LFP

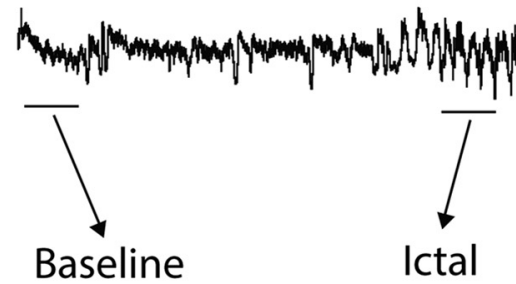

B
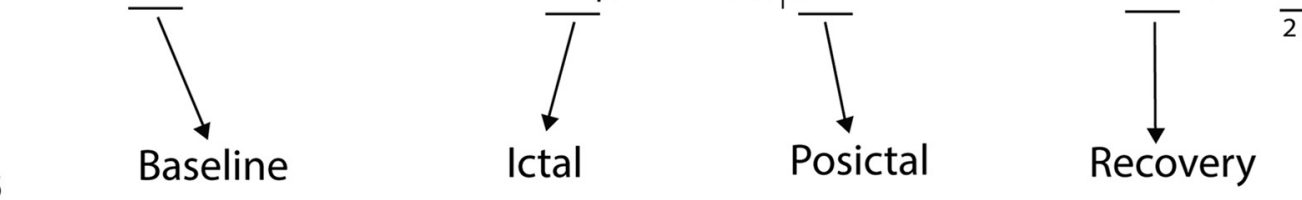

HC LFP
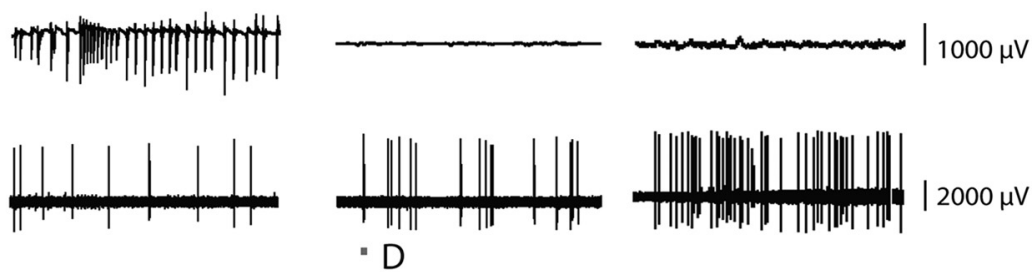

CL SUA

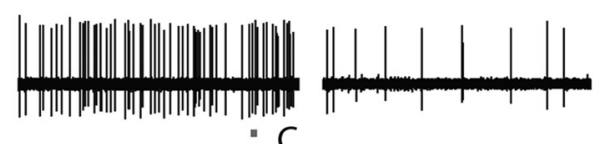

" D

LO MUA
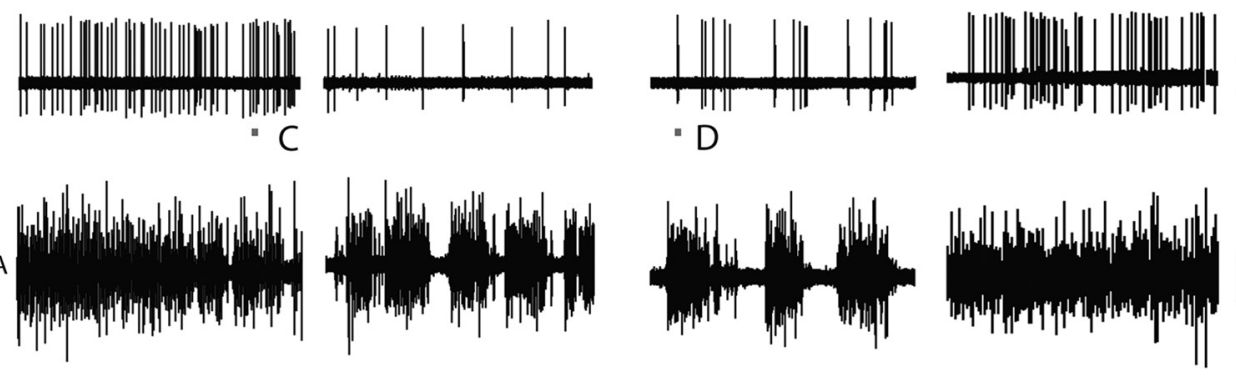

$2000 \mu \mathrm{V}$

LO LFP
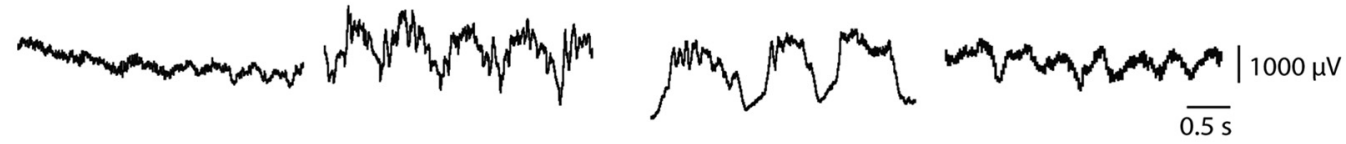

\section{Tonic Firing}

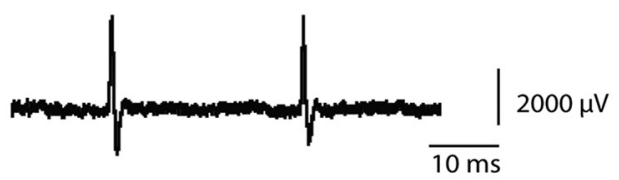

D Burst Firing

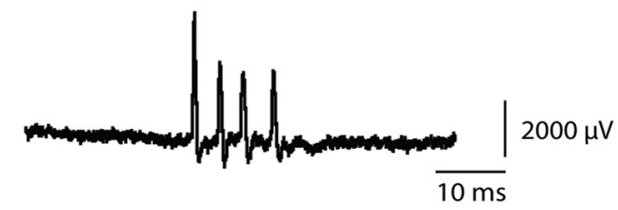

Figure 5. Thalamic CL neuron decreases firing during focal limbic seizure. $A$, Seizure induced by $2 \mathrm{~s}$ stimulation of the hippocampus. After the stimulus, fast polyspike activity is seen in the hippocampal LFP (HCLFP). SUA in the thalamic CL nucleus showed decreased firing during seizure activity, which slowly recovered in the postictal period. LO frontal cortex showed tonic firing of MUA and low voltage fast activity on LFP recordings at baseline. During seizures, this converted to slow waves on LFP accompanied by up and down states of MUA firing, which gradually recovered in the postictal period. $\boldsymbol{B}$, Expanded segments of data from baseline, ictal, postictal, and recovery epochs are magnified from the labeled region in $\boldsymbol{A}$. $\boldsymbol{C}$, Example of tonic firing from SUA recording in CL is magnified from the labeled region in baseline of $\boldsymbol{B}$. $\boldsymbol{D}$, Example of burst firing from SUA recording in $C L$ is magnified from the labeled region in postictal of $\boldsymbol{B}$. Bursts were defined as two or more spikes with $|S| \leq 10 \mathrm{~ms}$.

recordings, we found markedly reduced population firing of neurons in CL, but a tendency toward increased firing in ANT. VPM demonstrated a notable increase in spindle waves during focal seizures. Consistent with decreased MUA in CL, juxtacellular recordings from single neurons in CL revealed decreased overall firing rate but an increase in burst firing after seizure initiation, which gradually recovered during the postictal period. These findings confirm our hypothesis that some thalamocortical net- works participate directly in increased neuronal firing during focal limbic seizures, whereas other thalamocortical networks exhibit depressed physiology resembling deep sleep, which may contribute to impaired consciousness.

Although the important role of the CL nucleus of the thalamus in modulation of consciousness has long been recognized (Glenn and Steriade, 1982; Gottesmann, 1999; Paus, 2000; Schiff et al., 2013), CL's role in loss of consciousness during focal limbic sei- 
A

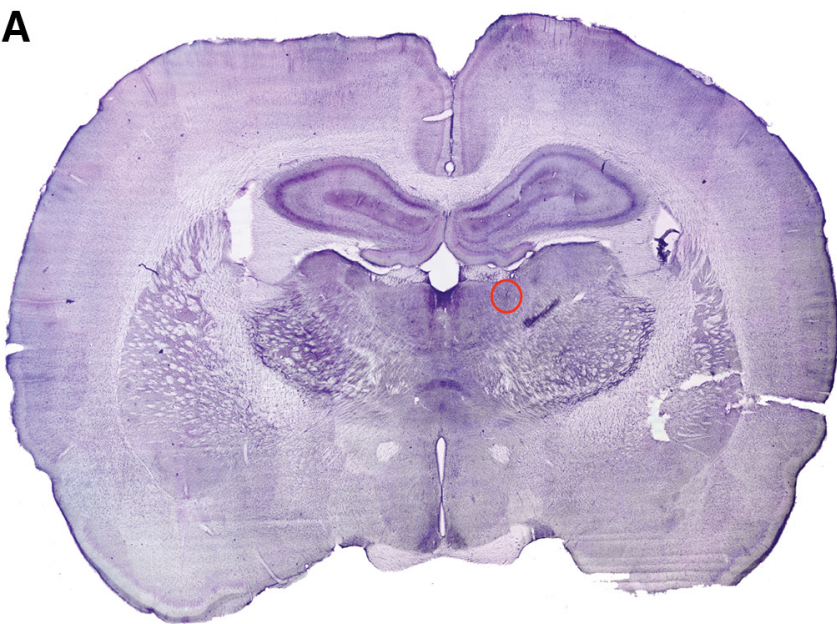

B

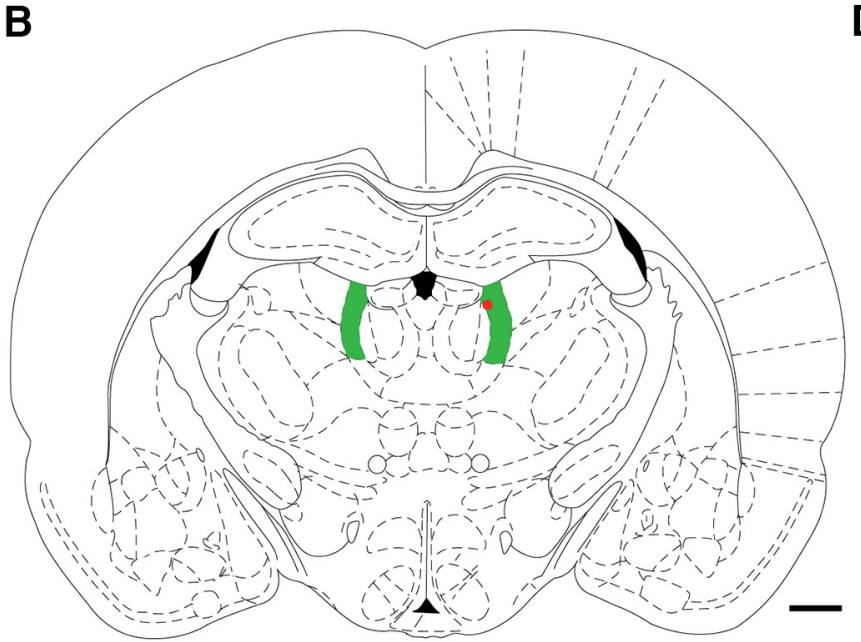

bregma $-2.8 \mathrm{~mm}$
C

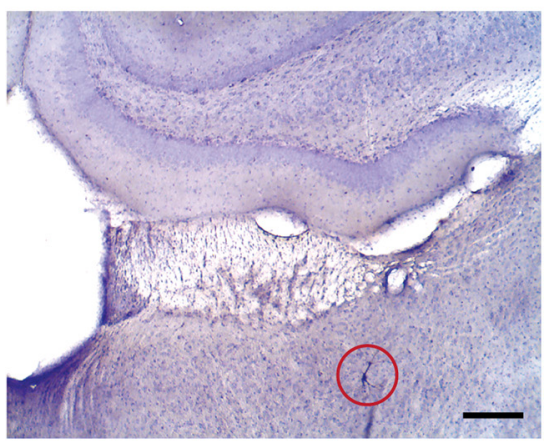

D

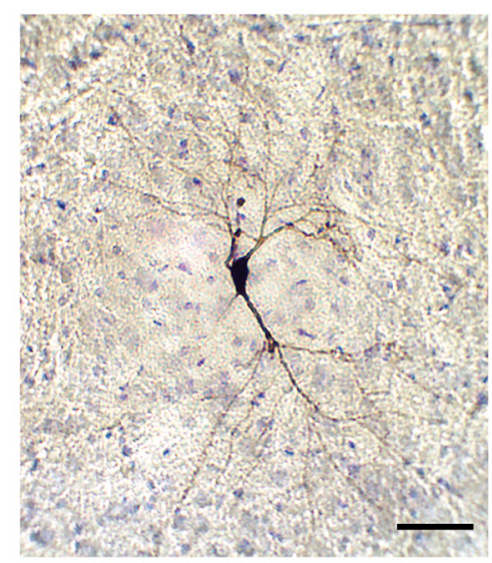

E

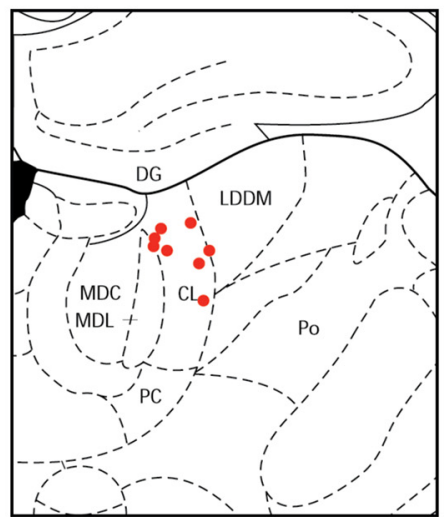

Bregma $-2.8 \mathrm{~mm}$

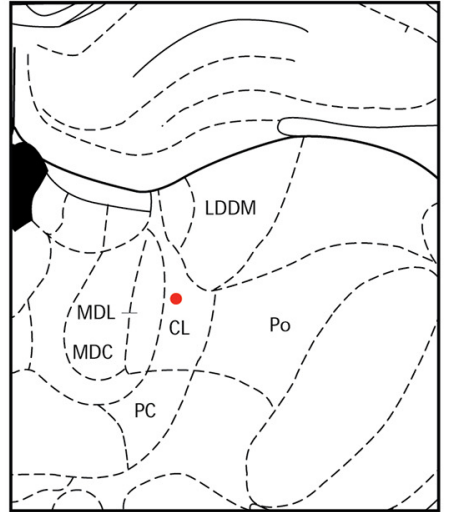

Bregma $-3.14 \mathrm{~mm}$

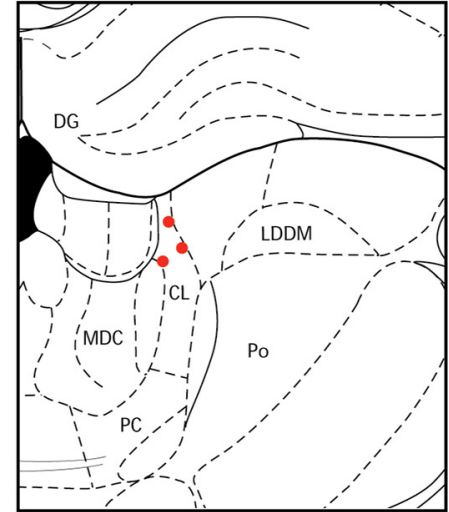

Bregma $-3.3 \mathrm{~mm}$

Figure 6. Histology of neurons studied by juxtacellular recordings in $C L$ thalamus. $\boldsymbol{A}, \boldsymbol{B}$, Example image of Ni-DAB (neurobiotin) stained positive neuron placement in CL nucleus of the thalamus (CL) and corresponding atlas coronal section at anteroposterior $\sim-2.8 \mathrm{~mm}$. Location of neuron is indicated by red circle in $\boldsymbol{A}$, and by red dot in $\boldsymbol{B}$. C, $\boldsymbol{D}$, Progressively enlarged views of section in $\boldsymbol{A}$, showing labeled neuron recorded juxtacellularly, stained for DAB on a background stain of cresyl violet. Soma and neurites can be seen clearly in $\mathbf{D}$. $\boldsymbol{E}$, Locations of all recorded neurons in thalamic $\mathrm{CL}$ ( $n=12$ neurons, $n=8$ animals). MDC, Mediodorsal nucleus of thalamus, central part; MDL, mediodorsal nucleus of thalamus, lateral part; LDDM, laterodorsal nucleus of thalamus, dorsomedial part; PC, paracentral nucleus of thalamus; P0, posterior nuclear group of thalamus; DG, dentate gyrus. $\boldsymbol{B}, \boldsymbol{E}$, Coronal section schematics reproduced with permission from Paxinos and Watson (1998). Scale bars: $\boldsymbol{B}, 1 \mathrm{~mm} ; \boldsymbol{C}, 200 \mu \mathrm{m} ; \boldsymbol{D}, 50 \mu \mathrm{m}$. 
A

Baseline

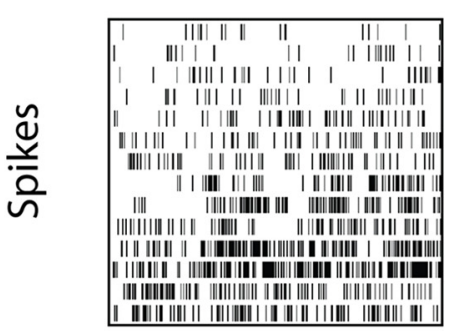

B

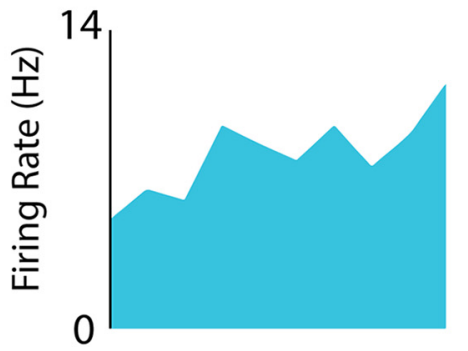

C

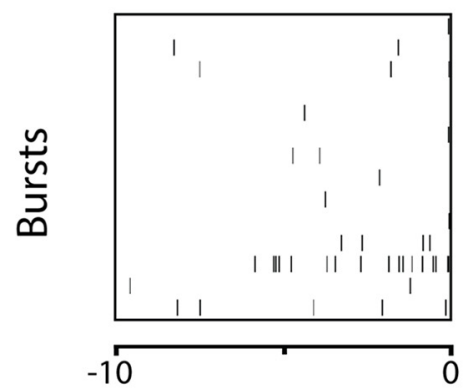

Ictal
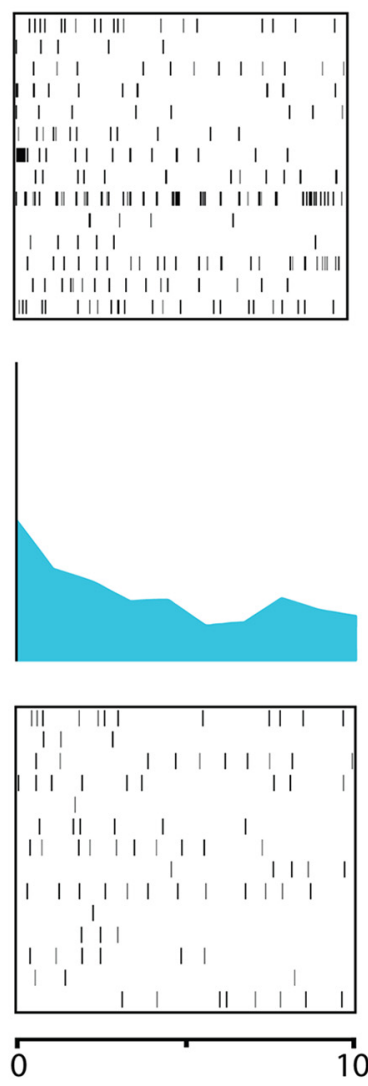

Time (Seconds)

\section{Postictal}
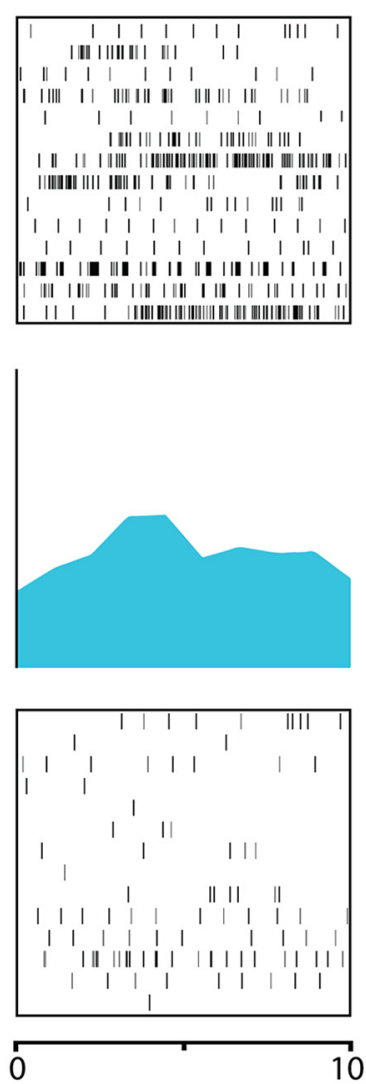

D
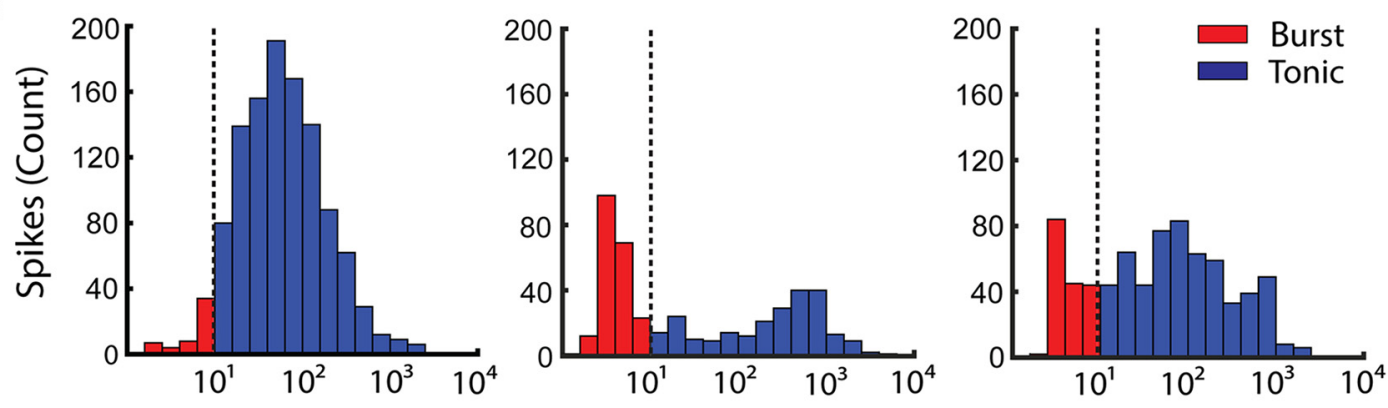

Interspike Interval (Milliseconds)

E
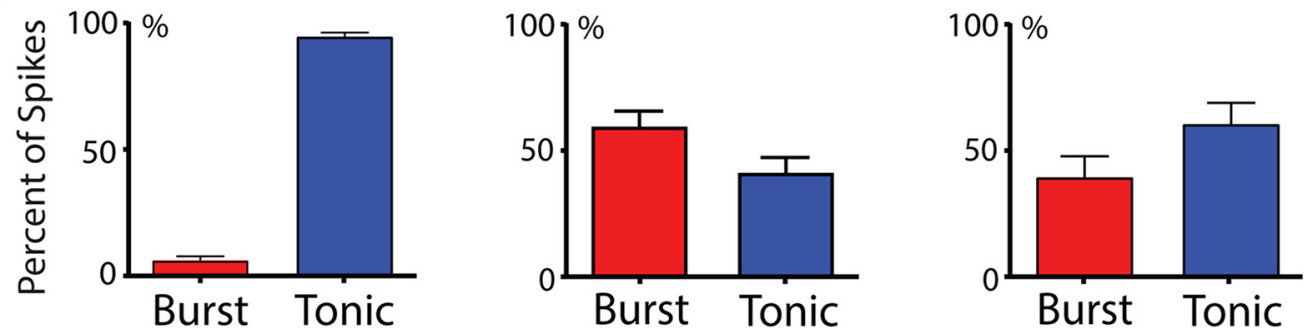

Figure 7. Thalamic CL nucleus single-unit recordings show decreased mean firing rate but increased burst firing during seizures. $\boldsymbol{A}$, Raster plot of spikes in identified neurons from the thalamic CL nucleus (12 cells from 8 animals, 14 seizures). Each line indicates one spike. $\boldsymbol{B}$, Mean firing rate histogram data presented as curvilinear plots with firing rates in $1 \mathrm{~s}$ nonoverlapping bins. $\boldsymbol{C}$, Raster plot of burst firing from identified CL neurons (12 cells from 8 animals, 14 seizures). Each line indicates one burst of $\geq 2$ spikes. Horizontal time axes beneath $\boldsymbol{C}$ apply to $\boldsymbol{A}$ and $\boldsymbol{B}$ as well. $\boldsymbol{D}$, ISI histogram data presented with logarithmically spaced bins. Overall number of spikes (total count of spikes across all neurons shown in $\boldsymbol{A}, \boldsymbol{B}$ ) decreases in the ictal period, and also makes a transition in firing pattern to a predominance of burst firing (red) rather than tonic firing (blue). $\boldsymbol{E}$, Percentage of spikes in burst versus tonic (nonburst) firing patterns during baseline, ictal, and postictal periods. The proportion of spikes in burst firing pattern was significantly higher in both the ictal and postictal periods compared with baseline $\left(\chi^{2}=634.1,223.6\right.$, respectively, $\left.p<0.0001\right)$. $\boldsymbol{A}-\boldsymbol{E}$, Data are from the $10 \mathrm{~s}$ baseline immediately before seizures, the first $10 \mathrm{~s}$ after seizure onset, and the first $10 \mathrm{~s}$ after seizures end in the postictal period. Burst firing was defined as $\geq 2$ consecutive action potentials with an $|S| \leq 10 \mathrm{~ms}$. Anatomical locations of all recorded neurons are shown in Figure $6 E$. 
zures has been relatively neglected. Considering that thalamic CL has long been implicated in arousal, working both cooperatively and independently by projecting excitatory innervation to activate widespread regions of cortex, suppression of the intralaminar thalamus would be well suited to contribute to depressed cortical activity during seizures (Steriade et al., 1993a; Poulet et al., 2012). Thalamic CL stimulation in both human patients and animal models can induce cortical desynchronization and improve functional outcomes, including behavior, and arousal in disorders of consciousness, including epilepsy (Schiff et al., 2007; Gummadavelli et al., 2015a; Kundishora et al., 2017). A recent fMRI study in the animal model with focal limbic seizures displayed a decrease in BOLD signal in thalamic CL paired with decreased cortical fMRI activity during and following seizures (Motelow et al., 2015). However, the electrophysiological basis of the decreased BOLD signal in CL has not previously been investigated through direct neuronal recordings. These are necessary because (1) in some cases, BOLD signals do not accurately reflect underlying neuronal activity especially during seizures (Schridde et al., 2008; Mishra et al., 2011); and (2) only direct neuronal recordings can reveal detailed changes in neuronal firing pattern (e.g., burst vs tonic firing). Our findings further confirm the intimate relationship between CL activation and cortical arousal. Direct recordings from the CL identified decreased neuronal activity during focal limbic seizures, which may lead to decreased excitatory output projecting to the frontal cortex, and could in turn contribute to cortical slow waves and suppressed function. This hypothesis was not directly tested in this study; however, it is supported by the fact that electrical stimulation of CL reverses cortical slow waves and improves behavioral arousal during and following focal limbic seizures (Gummadavelli et al., 2015b; Kundishora et al., 2017). Future work could provide additional insights through selective optogenetic activation of CL neurons, as has been done previously in this model in other regions (Furman et al., 2015).

Interestingly, we also found that most neurons in the thalamic CL converted to a burst firing pattern during seizures but fired with single spikes during baseline and after recovery. Normally, the neurons in the CL and other thalamic nuclei exhibit two distinct firing modes: tonic and burst firing. These modes reflect the status of voltage-dependent, intrinsic membrane conductance, including low-threshold calcium currents, which recover from inactivation and generate low-threshold calcium spikes with superimposed bursts when the membrane potential is hyperpolarized (Sherman, 2001). Both response modes interact with the cortex but respond differently to incoming inputs (Glenn and Steriade, 1982; Sherman, 2001). Previous research has revealed that tonic firing is related to brain-activated states of waking and rapid eye movement sleep, whereas rhythmic bursting usually appears during slow-wave sleep, deep anesthesia, or some pathological disorders involving loss of consciousness (Livingstone and Hubel, 1981; Glenn and Steriade, 1982; Steriade et al., 1993b). Evidence of burst and tonic firing of thalamic neurons has been reported in various species, including cats, rats, monkeys, and humans (Guido and Weyand, 1995; Nicolelis et al., 1995; Tsoukatos et al., 1997; Ramcharan et al., 2001). Our single-neuron firing recordings in CL showed a rapid transition from tonic firing to burst firing mode during seizures, indicating a state change in neurons in the CL after seizure initiation. The present juxtacellular recordings were done only in CL as an example of a thalamic nucleus involved in arousal, although similar changes are likely in other nuclei as well and could be investigated through future studies during seizures. Considering that burst firing is a pattern similar to that found in slow-wave sleep or deep anesthesia, our findings suggest depressed arousal of the CL and possibly other re- gions of the thalamus, which may contribute to suppressed activity of the cortex. Prior recordings from cholinergic neurons in the pedunculopontine tegmental nucleus, electrochemical measurements of cholinergic neurotransmission in the intralaminar thalamus, and optogenetic restoration of cholinergic inputs suggest that incoming cholinergic arousal as well as other neuromodulatory transmitters may be depressed during focal limbic seizures (Furman et al., 2015; Li et al., 2015; Motelow et al., 2015; Zhan et al., 2016). Our results provide more evidence for the network inhibition hypothesis (Norden and Blumenfeld, 2002; Blumenfeld, 2012), indicating that decreased subcortical arousal could be a critical mechanism for loss of consciousness in focal temporal lobe seizures.

Additionally, as a suitable target for neurostimulation in patients with medically refractory epilepsy, the anterior nuclear group (ANT) is one of the most important regions in the thalamus. ANT occupies the superior region of the thalamus and has both direct and indirect reciprocal connections with the hippocampal formation (Aggleton et al., 2010; Child and Benarroch, 2013). It is usually considered as a component of the "extended hippocampal system" (Vann and Aggleton, 2004). Although the anatomic connections and excitatory influences of the ANT of the thalamus are well known, its physiological role in limbic seizures is not fully understood. We examined the role of the ANT of the thalamus by MUA recording in an established rodent seizure model, and found that the ANT generally demonstrated opposite MUA changes compared with the CL. The ANT showed a trend toward increased neuronal firing during ictal periods along with significant postictal suppression correlating with epileptic discharges in the hippocampus (and postictal suppression), which suggests that the ANT may be involved in seizure propagation and maintenance in focal limbic seizures (Hamani et al., 2004; Takebayashi et al., 2007). High-frequency electrical stimulation in the ANT may suppress its normal function in seizure amplification, rebalancing glutamate and GABA levels in the hippocampal circuit (Liu et al., 2012), and improve seizure control. Our work provides more experimental evidence to support clinical applications of deep brain stimulation in the ANT of the thalamus during focal limbic seizures.

We also found that, coincident with slow oscillation in the cortex, MUA recordings from the VPM demonstrated a notable increase in spindle waves during focal seizures, which persisted into the postictal period and then gradually recovered. Previous studies have suggested that spindles are generated in the thalamus, through a rhythmic interaction of excitatory neurons in several thalamic nuclei, particularly the relay nuclei (including VPM) and inhibitory neurons of the nucleus reticularis thalami (nRT) (Steriade et al., 1985; von Krosigk et al., 1993). Both the VPM and $\mathrm{nRT}$ receive dense ascending cholinergic projections from the brainstem (Hallanger et al., 1987), which can excite VPM cells through M1-type muscarinic receptors, but inhibit nRT cells via M2-type receptors (Zhu and Uhlrich, 1998; Carden and Bickford, 1999; Plummer et al., 1999). Recent research has provided new evidence that decreased subcortical cholinergic arousal may be involved in the modulation of loss of consciousness during and following focal temporal lobe seizures (Furman et al., 2015; Li et al., 2015; Motelow et al., 2015). We can speculate that seizure initiation reduces cholinergic arousal in VPM and simultaneously disinhibits GABAergic neurons in the nRT, increasing synchronized burst firing and inducing more IPSPs in the VPM, both contributing to sleep spindle oscillation production in thalamocortical networks. Previous studies suggest that sleep spindles interrupt afferent thalamocortical information flow and reduce perception of external sensory information during sleep (Cote et al., 
2000; Kakigi et al., 2003), and the present work raises the novel possibility that some thalamocortical networks may similarly be affected during and following focal seizures.

The present work is limited in several ways but lays the groundwork for additional important future studies. For example, we found very different activity patterns in different thalamic nuclei; however, anesthetic agents, even the "light" anesthesia protocol we used, could alter neuronal activity. Prior studies without anesthesia in human patients and in animal models of focal limbic seizures demonstrated two patterns of activity: either seizure-like ictal increases in activity or sleep-like decreases in activity in different cortical-subcortical networks based on EEG or functional neuroimaging (Blumenfeld et al., 2004a, b; Englot et al., 2008, 2009; 2010; Gummadavelli et al., 2015a; Kundishora et al., 2017). The present study is the first to examine this activity at the level of single neurons in different thalamic nuclei, albeit under anesthesia. Although more technically challenging, it will be crucial in future studies to extend these single-unit and multiunit measurements to unanesthetized freely moving animals. Another important direction for future studies will be to investigate the relative contributions of cortex and thalamus to the observed changes in activity patterns. For example, it would be of interest to optogenetically silence either thalamic or corresponding cortical neurons selectively to determine whether one or the other may make more important contributions to initiating sleep spindles during focal limbic seizures. Another important area for future work is the activity pattern of different thalamic nuclei in secondarily generalized seizures. Although they have focal onset, prior work suggests that secondarily generalized seizures engage widespread hippocampal, neocortical, and thalamic networks in intense seizure activity without the marked regional thalamic differences reported here (Nersesyan et al., 2004; Englot et al., 2008; DeSalvo et al., 2010); however, this has not yet been investigated on the cellular level.

In conclusion, the present study demonstrates divergent activity patterns in three different thalamic nuclei during focal limbic seizures. Although further work is needed, we can speculate based on these results and previous work that some thalamic nuclei participate more directly in seizure propagation, whereas others may play a vital role in depressed cortical arousal and impaired consciousness. This is an important first step in directly recognizing the complicated connections, functions, and organization of the thalamus during focal limbic seizures. In addition, the availability of these findings regarding each region's neuronal activity changes in acute seizures can greatly facilitate future studies of subcortical networks and may help guide clinical treatments aimed at preventing specific abnormal activity patterns in different thalamocortical networks during focal limbic seizures.

\section{References}

Aggleton JP, O'Mara SM, Vann SD, Wright NF, Tsanov M, Erichsen JT (2010) Hippocampal-anterior thalamic pathways for memory: uncovering a network of direct and indirect actions. Eur J Neurosci 31:2292-2307. CrossRef Medline

Benedek K, Juhász C, Muzik O, Chugani DC, Chugani HT (2004) Metabolic changes of subcortical structures in intractable focal epilepsy. Epilepsia 45:1100-1105. CrossRef Medline

Bertram EH, Zhang DX, Mangan P, Fountain N, Rempe D (1998) Functional anatomy of limbic epilepsy: a proposal for central synchronization of a diffusely hyperexcitable network. Epilepsy Res 32:194-205. CrossRef Medline

Blumenfeld H (2012) Impaired consciousness in epilepsy. Lancet Neurol 11:814-826. CrossRef Medline

Blumenfeld H (2014) What is a seizure network? Long-range network consequences of focal seizures. Adv Exp Med Biol 813:63-70. CrossRef Medline
Blumenfeld H, Rivera M, McNally KA, Davis K, Spencer DD, Spencer SS (2004a) Ictal neocortical slowing in temporal lobe epilepsy. Neurology 63:1015-1021. CrossRef Medline

Blumenfeld H, McNally KA, Vanderhill SD, Paige AL, Chung R, Davis K, Norden AD, Stokking R, Studholme C, Novotny EJ Jr, Zubal IG, Spencer SS (2004b) Positive and negative network correlations in temporal lobe epilepsy. Cereb Cortex 14:892-902. CrossRef Medline

Carden WB, Bickford ME (1999) Location of muscarinic type 2 receptors within the synaptic circuitry of the cat visual thalamus. J Comp Neurol 410:431-443. CrossRef Medline

Chen L, Deng Y, Luo WH, Wang Z, Zeng SQ (2009) Detection of bursts in neuronal spike trains by the mean inter-spike interval method. Prog Nat Sci 19:229-235. CrossRef

Child ND, Benarroch EE (2013) Anterior nucleus of the thalamus: functional organization and clinical implications. Neurology 81:1869-1876. CrossRef Medline

Contreras D, Steriade M (1996) Spindle oscillation in cats: the role of corticothalamic feedback in a thalamically generated rhythm. J Physiol 490: 159-179. CrossRef Medline

Cote KA, Epps TM, Campbell KB (2000) The role of the spindle in human information processing of high-intensity stimuli during sleep. J Sleep Res 9:19-26. CrossRef Medline

DeSalvo MN, Schridde U, Mishra AM, Motelow JE, Purcaro MJ, Danielson N, Bai X, Hyder F, Blumenfeld H (2010) Focal BOLD fMRI changes in bicuculline-induced tonic-clonic seizures in the rat. Neuroimage 50:902909. CrossRef Medline

Duque A, Zaborszky L (2006) Juxtacellular labeling of individual neurons in vivo: from electrophysiology to synaptology. In: Neuroanatomical tracttracing, Vol 3, pp 197-236. New York: Springer.

Englot DJ, Mishra AM, Mansuripur PK, Herman P, Hyder F, Blumenfeld H (2008) Remote effects of focal hippocampal seizures on the rat neocortex. J Neurosci 28:9066-9081. CrossRef Medline

Englot DJ, Modi B, Mishra AM, DeSalvo M, Hyder F, Blumenfeld H (2009) Cortical deactivation induced by subcortical network dysfunction in limbic seizures. J Neurosci 29:13006-13018. CrossRef Medline

Englot DJ, Yang L, Hamid H, Danielson N, Bai X, Marfeo A, Yu L, Gordon A, Purcaro MJ, Motelow JE, Agarwal R, Ellens DJ, Golomb JD, Shamy MC, Zhang H, Carlson C, Doyle W, Devinsky O, Vives K, Spencer DD, et al. (2010) Impaired consciousness in temporal lobe seizures: role of cortical slow activity. Brain 133:3764-3777. CrossRef Medline

Escueta AV, Bacsal FE, Treiman DM (1982) Complex partial seizures on closed-circuit television and EEG: a study of 691 attacks in 79 patients. Ann Neurol 11:292-300. CrossRef Medline

Furman M, Zhan Q, McCafferty C, Lerner BA, Motelow JE, Meng J, Ma C, Buchanan GF, Witten IB, Deisseroth K, Cardin JA, Blumenfeld H (2015) Optogenetic stimulation of cholinergic brainstem neurons during focal limbic seizures: effects on cortical physiology. Epilepsia 56:e198-202. CrossRef Medline

Glenn LL, Steriade M (1982) Discharge rate and excitability of cortically projecting intralaminar thalamic neurons during waking and sleep states. J Neurosci 2:1387-1404. Medline

Gottesmann C (1999) The neurophysiology of sleep and waking: intracerebral connections, functioning and ascending influences of the medulla oblongata. Prog Neurobiol 59:1-54. CrossRef Medline

Guido W, Weyand T (1995) Burst responses in thalamic relay cells of the awake behaving cat. J Neurophysiol 74:1782-1786. Medline

Gummadavelli A, Motelow JE, Smith N, Zhan Q, Schiff ND, Blumenfeld H (2015a) Thalamic stimulation to improve level of consciousness after seizures: evaluation of electrophysiology and behavior. Epilepsia 56:114124. CrossRef Medline

Gummadavelli A, Kundishora AJ, Willie JT, Andrews JP, Gerrard JL, Spencer DD, Blumenfeld H (2015b) Neurostimulation to improve level of consciousness in patients with epilepsy. Neurosurg Focus 38:E10. CrossRef Medline

Hallanger AE, Levey AI, Lee HJ, Rye DB, Wainer BH (1987) The origins of cholinergic and other subcortical afferents to the thalamus in the rat. J Comp Neurol 262:105-124. CrossRef Medline

Hamani C, Ewerton FI, Bonilha SM, Ballester G, Mello LE, Lozano AM (2004) Bilateral anterior thalamic nucleus lesions and high-frequency stimulation are protective against pilocarpine-induced seizures and status epilepticus. Neurosurgery 54:191-195; discussion 195-197. CrossRef Medline 
He X, Doucet GE, Sperling M, Sharan A, Tracy JI (2015) Reduced thalamocortical functional connectivity in temporal lobe epilepsy. Epilepsia 56: 1571-1579. CrossRef Medline

Janszky J, Schulz R, Janszky I, Ebner A (2004) Medial temporal lobe epilepsy: gender differences. J Neurol Neurosurg Psychiatry 75:773-775. CrossRef Medline

Kakigi R, Naka D, Okusa T, Wang X, Inui K, Qiu Y, Tran TD, Miki K, Tamura Y, Nguyen TB, Watanabe S, Hoshiyama M (2003) Sensory perception during sleep in humans: a magnetoencephalograhic study. Sleep Med 4:493-507. CrossRef Medline

Keller SS, Richardson MP, O’Muircheartaigh J, Schoene-Bake JC, Elger C, Weber B (2015) Morphometric MRI alterations and postoperative seizure control in refractory temporal lobe epilepsy. Hum Brain Mapp 36: 1637-1647. CrossRef Medline

Kros L, Eelkman Rooda OH, Spanke JK, Alva P, van Dongen MN, Karapatis A, Tolner EA, Strydis C, Davey N, Winkelman BH, Negrello M, Serdijn WA, Steuber V, van den Maagdenberg AM, De Zeeuw CI, Hoebeek FE (2015) Cerebellar output controls generalized spike-and-wave discharge occurrence. Ann Neurol 77:1027-1049. CrossRef Medline

Kundishora AJ, Gummadavelli A, Ma C, Liu M, McCafferty C, Schiff ND, Willie JT, Gross RE, Gerrard J, Blumenfeld H (2017) Restoring conscious arousal during focal limbic seizures with deep brain stimulation. Cereb Cortex 27:1964-1975. CrossRef Medline

Li W, Motelow JE, Zhan Q, Hu YC, Kim R, Chen WC, Blumenfeld H (2015) Cortical network switching: possible role of the lateral septum and cholinergic arousal. Brain Stimul 8:36-41. CrossRef Medline

Lim SN, Lee ST, Tsai YT, Chen IA, Tu PH, Chen JL, Chang HW, Su YC, Wu $T$ (2007) Electrical stimulation of the anterior nucleus of the thalamus for intractable epilepsy: a long-term follow-up study. Epilepsia 48:342347. CrossRef Medline

Liu HG, Yang AC, Meng DW, Chen N, Zhang JG (2012) Stimulation of the anterior nucleus of the thalamus induces changes in amino acids in the hippocampi of epileptic rats. Brain Res 1477:37-44. CrossRef Medline

Livingstone MS, Hubel DH (1981) Effects of sleep and arousal on the processing of visual information in the cat. Nature 291:554-561. CrossRef Medline

Llinás RR, Steriade M (2006) Bursting of thalamic neurons and states of vigilance. J Neurophysiol 95:3297-3308. CrossRef Medline

Mejías-Aponte CA, Jiménez-Rivera CA, Segarra AC (2002) Sex differences in models of temporal lobe epilepsy: role of testosterone. Brain Res 944: 210-218. CrossRef Medline

Mirski MA, Rossell LA, Terry JB, Fisher RS (1997) Anticonvulsant effect of anterior thalamic high frequency electrical stimulation in the rat. Epilepsy Res 28:89-100. CrossRef Medline

Mishra AM, Ellens DJ, Schridde U, Motelow JE, Purcaro MJ, DeSalvo MN, Enev M, Sanganahalli BG, Hyder F, Blumenfeld H (2011) Where fMRI and electrophysiology agree to disagree: corticothalamic and striatal activity patterns in the WAG/Rij rat. J Neurosci 31:15053-15064. CrossRef Medline

Motelow JE, Li W, Zhan Q, Mishra AM, Sachdev RN, Liu G, Gummadavelli A, Zayyad Z, Lee HS, Chu V, Andrews JP, Englot DJ, Herman P, Sanganahalli BG, Hyder F, Blumenfeld H (2015) Decreased subcortical cholinergic arousal in focal seizures. Neuron 85:561-572. CrossRef Medline

Nersesyan H, Hyder F, Rothman DL, Blumenfeld H (2004) Dynamic fMRI and EEG recordings during spike-wave seizures and generalized tonicclonic seizures in WAG/Rij rats. J Cereb Blood Flow Metab 24:589-599. CrossRef Medline

Nicolelis MA, Baccala LA, Lin RC, Chapin JK (1995) Sensorimotor encoding by synchronous neural ensemble activity at multiple levels of the somatosensory system. Science 268:1353-1358. CrossRef Medline

Norden AD, Blumenfeld H (2002) The role of subcortical structures in human epilepsy. Epilepsy Behav 3:219-231. CrossRef Medline

Paus T (2000) Functional anatomy of arousal and attention systems in the human brain. Prog Brain Res 126:65-77. CrossRef Medline

Paxinos G, Watson C (1998) The rat brain in stereotaxic coordinates, Ed 4. San Diego: Academic.

Pinault D (1996) A novel single-cell staining procedure performed in vivo under electrophysiological control: morpho-functional features of juxtacellularly labeled thalamic cells and other central neurons with biocytin or Neurobiotin. J Neurosci Methods 65:113-136. CrossRef Medline
Plummer KL, Manning KA, Levey AI, Rees HD, Uhlrich DJ (1999) Muscarinic receptor subtypes in the lateral geniculate nucleus: a light and electron microscopic analysis. J Comp Neurol 404:408-425. CrossRef Medline

Poulet JF, Fernandez LM, Crochet S, Petersen CC (2012) Thalamic control of cortical states. Nat Neurosci 15:370-372. CrossRef Medline

Ramcharan EJ, Gnadt JW, Sherman SM (2001) The effects of saccadic eye movements on the activity of geniculate relay neurons in the monkey. Vis Neurosci 18:253-258. CrossRef Medline

Redecker C, Bruehl C, Hagemann G, Binus O, Witte OW (1997) Coupling of cortical and thalamic metabolism in experimentally induced visual and somatosensory focal epilepsy. Epilepsy Res 27:127-137. CrossRef Medline

Salanova V, Witt T, Worth R, Henry TR, Gross RE, Nazzaro JM, Labar D, Sperling MR, Sharan A, Sandok E, Handforth A, Stern JM, Chung S, Henderson JM, French J, Baltuch G, Rosenfeld WE, Garcia P, Barbaro NM, Fountain NB, et al. (2015) Long-term efficacy and safety of thalamic stimulation for drug-resistant partial epilepsy. Neurology 84:10171025. CrossRef Medline

Schiff ND, Giacino JT, Kalmar K, Victor JD, Baker K, Gerber M, Fritz B, Eisenberg B, Biondi T, O'Connor J, Kobylarz EJ, Farris S, Machado A, McCagg C, Plum F, Fins JJ, Rezai AR (2007) Behavioural improvements with thalamic stimulation after severe traumatic brain injury. Nature 448 : 600-603. CrossRef Medline

Schiff ND, Shah SA, Hudson AE, Nauvel T, Kalik SF, Purpura KP (2013) Gating of attentional effort through the central thalamus. J Neurophysiol 109:1152-1163. CrossRef Medline

Schridde U, Khubchandani M, Motelow JE, Sanganahalli BG, Hyder F, Blumenfeld H (2008) Negative BOLD with large increases in neuronal activity. Cereb Cortex 18:1814-1827. CrossRef Medline

Sherman SM (2001) Tonic and burst firing: dual modes of thalamocortical relay. Trends Neurosci 24:122-126. CrossRef Medline

Shmuel A, Augath M, Oeltermann A, Logothetis NK (2006) Negative functional MRI response correlates with decreases in neuronal activity in monkey visual area V1. Nat Neurosci 9:569-577. CrossRef Medline

Steriade M, Deschenes M (1984) The thalamus as a neuronal oscillator. Brain Res 320:1-63. Medline

Steriade M, Deschênes M, Domich L, Mulle C (1985) Abolition of spindle oscillations in thalamic neurons disconnected from nucleus reticularis thalami. J Neurophysiol 54:1473-1497. Medline

Steriade M, Amzica F, Nuñez A (1993a) Cholinergic and noradrenergic modulation of the slow (approximately $0.3 \mathrm{~Hz}$ ) oscillation in neocortical cells. J Neurophysiol 70:1385-1400. Medline

Steriade M, McCormick DA, Sejnowski TJ (1993b) Thalamocortical oscillations in the sleeping and aroused brain. Science 262:679-685. CrossRef Medline

Takebayashi S, Hashizume K, Tanaka T, Hodozuka A (2007) The effect of electrical stimulation and lesioning of the anterior thalamic nucleus on kainic acid-induced focal cortical seizure status in rats. Epilepsia 48:348 358. CrossRef Medline

Tsoukatos J, Kiss ZH, Davis KD, Tasker RR, Dostrovsky JO (1997) Patterns of neuronal firing in the human lateral thalamus during sleep and wakefulness. Exp Brain Res 113:273-282. CrossRef Medline

Van der Werf YD, Witter MP, Groenewegen HJ (2002) The intralaminar and midline nuclei of the thalamus: anatomical and functional evidence for participation in processes of arousal and awareness. Brain Res Brain Res Rev 39:107-140. CrossRef Medline

Vann SD, Aggleton JP (2004) The mammillary bodies: two memory systems in one? Nat Rev Neurosci 5:35-44. CrossRef Medline

von Krosigk M, Bal T, McCormick DA (1993) Cellular mechanisms of a synchronized oscillation in the thalamus. Science 261:361-364. CrossRef Medline

Wright NF, Vann SD, Erichsen JT, O’Mara SM, Aggleton JP (2013) Segregation of parallel inputs to the anteromedial and anteroventral thalamic nuclei of the rat. J Comp Neurol 521:2966-2986. CrossRef Medline

Zhan Q, Buchanan GF, Motelow JE, Andrews J, Vitkovskiy P, Chen WC, Serout F, Gummadavelli A, Kundishora A, Furman M, Li W, Bo X, Richerson GB, Blumenfeld H (2016) Impaired serotonergic brainstem function during and after seizures. J Neurosci 36:2711-2722. CrossRef Medline

Zhu JJ, Uhlrich DJ (1998) Cellular mechanisms underlying two muscarinic receptor-mediated depolarizing responses in relay cells of the rat lateral geniculate nucleus. Neuroscience 87:767-781. CrossRef Medline 